\title{
On the Rapid Assessment of Mechanical Behavior of a Prototype Nickel-Based Superalloy using Small-Scale Testing
}

\author{
SABIN SULZER, ENRIQUE ALABORT, ANDRÉ NÉMETH, BRYAN ROEBUCK, \\ and ROGER REED
}

\begin{abstract}
An electro-thermal mechanical testing (ETMT) system is used to assess the mechanical behavior of a prototype single-crystal superalloy suitable for industrial gas turbine applications. Miniaturized testpieces of a few $\mathrm{mm}^{2}$ cross section are used, allowing relatively small volumes to be tested. Novel methods involving temperature ramping and stress relaxation are employed, with the quantitative data measured and then compared to conventional methods. Advantages and limitations of the ETMT system are identified; particularly for the rapid assessment of prototype alloys prior to scale-up to pilot-scale quantities, it is concluded that some significant benefits emerge.
\end{abstract}

https://doi.org/10.1007/s11661-018-4673-5

(c) The Author(s) 2018

\section{INTRODUCTION}

NEW alloy grades are never deployed without careful testing of their properties and performance under conditions close to those experienced in service. Such so-called qualification activities can be difficult and costly; this explains why the time needed to insert them into new applications can be notoriously long. ${ }^{[1-3]}$ Furthermore, processing costs for the production of pilot-scale material quantities can be excessively large - often too great to justify - thus leading to conservatism and undue emphasis on maintaining the status quo. Without a doubt, such challenges lead to a slackening in the pace of technological change.

Consider, for example, the assessment of the mechanical response of a material destined for high-temperature applications. The yield stress depends upon temperature, but also on the strain rate. The creep resistance depends upon temperature once again, but also on the stress level. Even before the cyclic loading needed to assess fatigue behavior or the effects of a biaxial or triaxial stress state are considered, the number of

SABIN SULZER and ANDRÉ NÉMETH are with the Department of Materials, University of Oxford, Parks Road, Oxford, OX1 3PH, UK. Contact e-mail: sabin.sulzer@materials.ox.ac.uk ENRIQUE ALABORT is with the Department of Engineering Science, University of Oxford. BRYAN ROEBUCK is with the National Physical Laboratory, Hampton Road, Teddington TW1 OLW, UK. ROGER REED is with Department of Materials, University of Oxford and also with the Department of Engineering Science, University of Oxford. Manuscript submitted January 18, 2018.

Article published online May 30, 2018 conditions for which mechanical tests are needed can quickly become very significant. The difficulties identified above are then exacerbated. Moreover, there is a traditional emphasis - even today - on the use of standard testpieces of traditional design, which can mean that substantial volumes of material are needed. Might there be better ways of approaching this problem?

The research reported in this paper was carried out with these ideas in mind. Miniaturized testpieces are used within a novel electro-thermal mechanical testing (ETMT) system ${ }^{[4]}$ to assess relatively small volumes of material, with nonetheless representative materials behavior being shown to arise. But we have aimed to go further. First, a novel temperature ramping test is devised to allow the rapid assessment of the athermal yielding behavior of a new material, from just a single non-isothermal test. Second, a stress relaxation test is used to quickly deduce the time-dependent response. In this way, materials behavior is extracted rapidly from a small number of tests. To garner confidence in our approaches, comparisons are made with more traditional techniques.

\section{EXPERIMENTAL METHOD}

\section{A. Material}

A single-crystal superalloy developed by Siemens Industrial Turbomachinery (SIT) was chosen for the present study. Its nominal composition in order of decreasing wt pct is Ni-Cr-Ta-Co-Al-W-Mo-Si-Hf-C-Ce, and is similar to that reported previously by Reed et al. ${ }^{[5]}$ This alloy is a candidate for future industrial gas turbine 
(IGT) applications and was designed to combine good oxidation, corrosion, creep, and thermal-mechanical fatigue (TMF) resistance. ${ }^{[5-7]}$ Single-crystal test bars of $16 \mathrm{~mm}$ diameter and $165 \mathrm{~mm}$ length were cast with near $\langle 001\rangle,\langle 011\rangle$, and $\langle 111\rangle$ crystal growth directions. Chemical analysis using XRF, GDMS, OES, and LECO showed very good agreement between the measured and nominal values. Impurity levels were confirmed to be far lower than the maximum values allowed by the specification.

All the bars were macro-etched to check for the absence of grain boundaries and were then subjected to $\mathrm{X}$-ray analysis using the Laue back-reflection technique to ensure their orientation differed by less than $15 \mathrm{deg}$ from the specified direction. Heat treatment consisted of solutioning at $1280^{\circ} \mathrm{C}$ for 5 hours, followed by primary aging at $1100{ }^{\circ} \mathrm{C}$ for 4 hours, and secondary aging at $850{ }^{\circ} \mathrm{C}$ for 20 hours, in each case concluding with gas fan cooling in argon. SEM images of test bar cross sections were obtained using a JEOL(C) JSM-6500F TM $^{\text {TM }}$ SEM operating at $20 \mathrm{keV}$ and are shown in Figure 1. The microstructure is characteristic of IGT superalloys, and is composed of cuboidal, secondary $\gamma^{\prime}$ precipitates with side lengths of $\approx 400 \mathrm{~nm}$ and spherical, tertiary $\gamma^{\prime}$ particles with diameters on the order of $10 \mathrm{~nm}$, embedded in the $\gamma$ matrix. Particle size distributions were analyzed using the image processing software package MIPAR $\odot{ }^{[8]}$ The estimated $\gamma^{\prime}$ volume fraction after heat treatment is $53 \mathrm{pct}$, close to the 58 pct predicted by Thermo-Calc and the TTNi8 Ni-alloy database.
The orientations of the six bars used to manufacture the test specimens for the present study were checked again using a Zeiss $\odot$ EVO $^{\text {TM }}$ MA10 SEM fitted with a high-speed Bruker@ Quantax e $\mathrm{e}^{-}$Flash $^{1000}$ EBSD detector. Areas of $3 \times 2.5 \mathrm{~mm}^{2}$ were scanned at $20 \mathrm{keV}$ with a $5-\mu \mathrm{m}$ step size. Average misorientations calculated using the EBSD results and standard deviations for each data set are given in Table I. EBSD orientations are also shown in the simplified inverse pole figure map in Figure 1.

Miniaturized ETMT blanks with a nominal size of either $40 \times 3 \times 1$ or $40 \times 4 \times 2 \mathrm{~mm}^{3}$ were manufactured along longitudinal bar directions by wire-guided electro-discharge machining (EDM). These blanks were further waisted via EDM to give nominal widths in the center of the testpiece of 1.1 and $2 \mathrm{~mm}$, respectively, as shown in Figure 2. The main advantage of the waisted geometry is that it enables using customized grips, which precisely fit the waist radius and which ensure correct alignment during testing.

A further benefit is that this geometry gives rise to a concentration of stress and temperature within the central region. This limits the influence of the anomalous yielding effect observed in nickel-based superalloys-i.e., an increase in yield strength with temperature - which could otherwise lead to higher levels of plastic deformation in cooler regions closer to the grips. The latter point is of particular importance in the context of the present work and is discussed in further detail in Section IV-A. Nonetheless, a parallel-sided section is maintained in the center of the
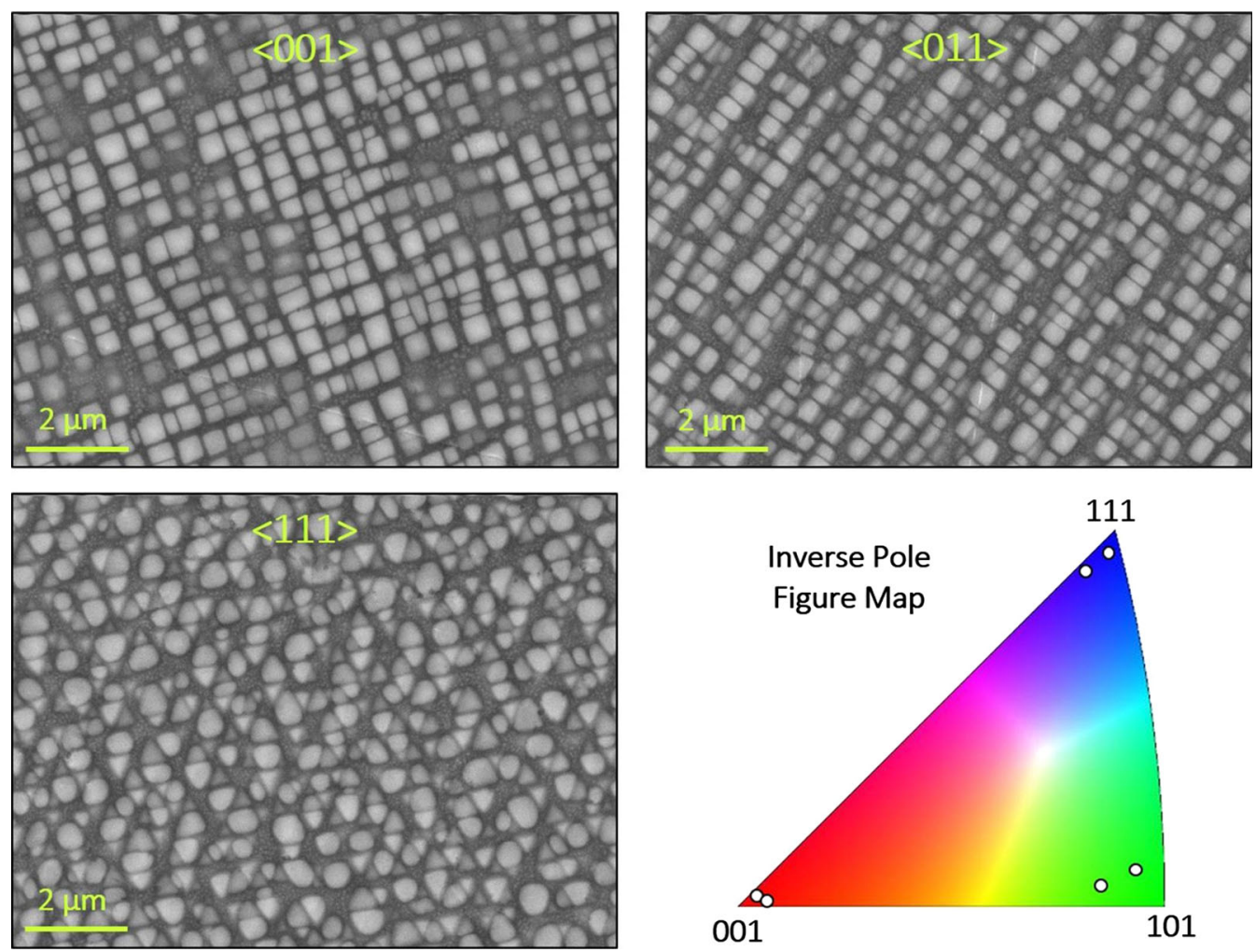

Fig. 1-SEM images of alloy microstructures and IPF map of test bar orientations. 
Table I. Results of Crystal Orientation Measurements with EBSD

\begin{tabular}{lcr}
\hline Test Bar & Average Misorientation (Deg) & Standard Deviation (Deg) \\
\hline$\langle 001\rangle 1$ & 2.39 & 0.56 \\
$\langle 001\rangle 2$ & 4.59 & 0.45 \\
$\langle 011\rangle 1$ & 2.86 & 2.40 \\
$\langle 011\rangle 2$ & 11.82 & 3.44 \\
$\langle 11\rangle 1$ & 0.90 & 0.92 \\
$\langle 11\rangle 2$ & 1.99 & 1.88 \\
\hline
\end{tabular}

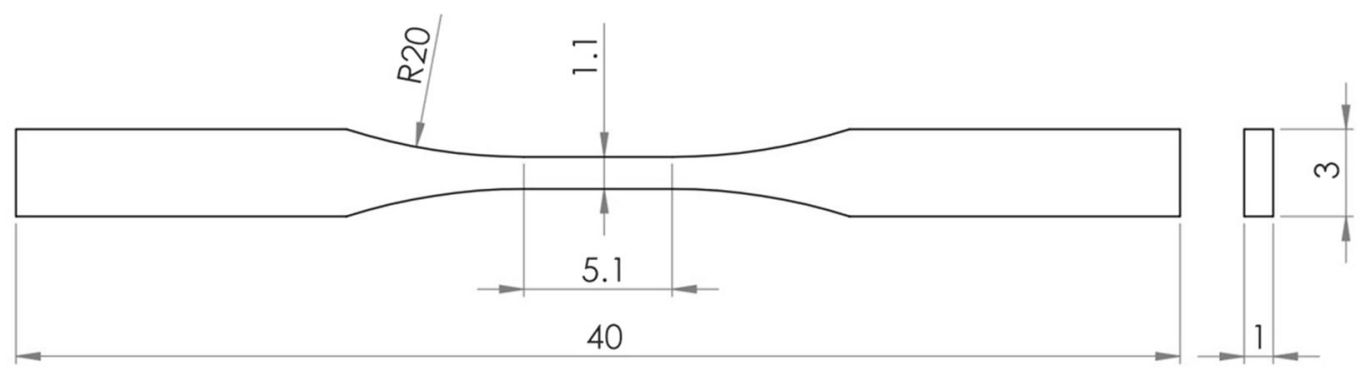

(a)

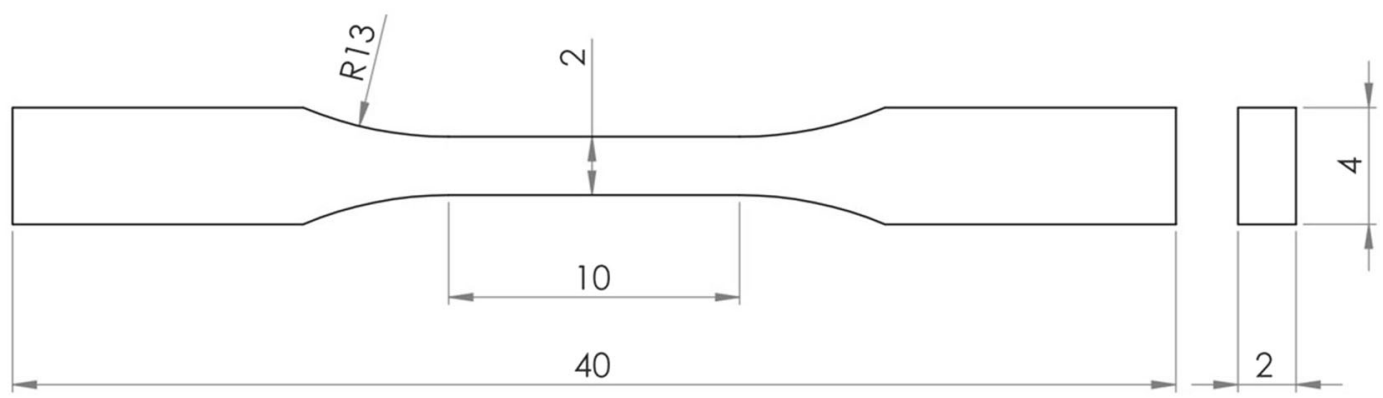

(b)

Fig. 2-ETMT specimen geometries used in the present study for $(a)$ verification tensile and stepped-temperature tests and $(b)$ stress relaxation tests (all measurements in $\mathrm{mm}$ ).

specimen to ensure a constant stress level and a uniform temperature distribution.

Surfaces were ground to a 4000-grit mirror finish using silicon carbide grinding paper. Besides ensuring a constant, repeatable finish, this step is crucial for removing the recast layer caused by EDM and for minimizing residual stresses in the sample prior to testing. ${ }^{[9]}$ The actual cross section dimensions were measured with a micrometer gauge for each specimen and were used to compute engineering stress. Lastly, each specimen was cleaned in an ultrasonic bath with ethanol, after which a high-temperature paint pattern for direct image correlation (DIC) was applied.

\section{B. The ETMT System}

Interest in high-temperature miniaturized testing has grown over time and has led to a multitude of approaches. ${ }^{[10-13]}$ However, ensuring accurate and reproducible results remains challenging, especially for the case of nickel-based superalloys, which must be qualified at very high temperatures, often close to their melting point. This makes the design and implementation of the load string, and of small-scale specimens, grips, and extensometers, difficult. The ETMT system was developed at the National Physical Laboratory (NPL) with these concerns in mind and has been used successfully for the characterization of $\gamma^{\prime}$ precipitate volume fraction, ${ }^{[14]}$ recrystallization kinetics, ${ }^{[15]}$ TMF ${ }^{[16,17]}$ flow stress, ${ }^{[4,18-20]}$ and creep strain evolution $^{[21,22]}$ in nickel-based superalloys.

The Instron ( ETMT system used in the present work is illustrated in Figure 3. It uses a mechanical loading assembly capable of testing in both tension and compression up to a maximum load of $5 \mathrm{kN}$. Load cell readings are based on a strain gauge element with integrated automatic calibration. A versatile gripping system allows the use of customized grips for each specimen geometry, in order to ensure correct alignment. Displacement of the top, moving grip can be 


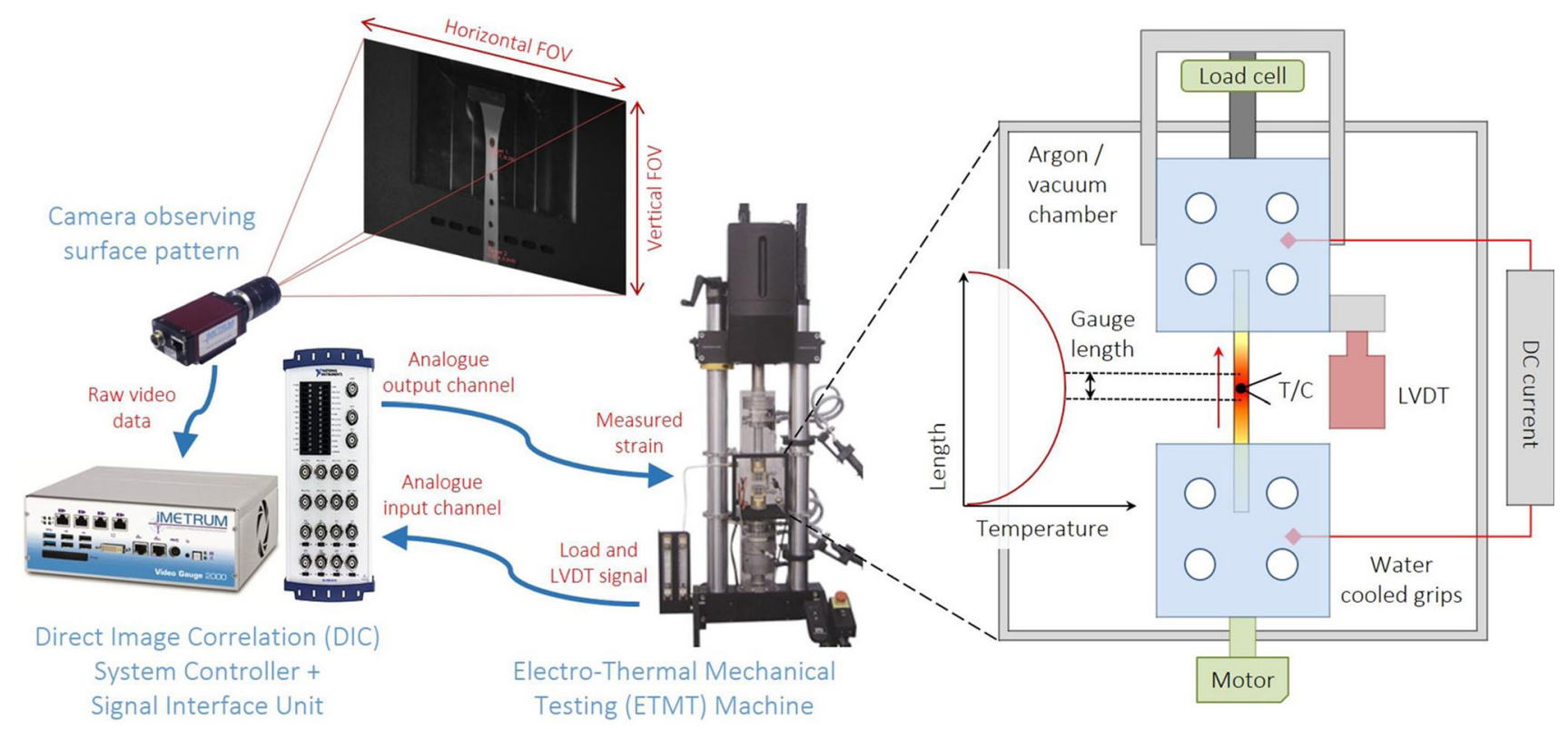

(a)

(b)

Fig. 3-(a) Overview of the testing system used for miniaturized testing of superalloys; images courtesy of Instron $\odot$ and Imetrum Ltd $\odot$. (b) Schematic illustration of ETMT components.

readily measured with an $\mathrm{LVDT}$, and strain at room temperature can be calculated after considering the initial grip separation.

Specimens are heated using a 400-A DC power supply via the Joule effect. An advantage - for example over furnace-based apparatus - is that a wide range of heating and cooling rates can be achieved and accurately controlled. The testing temperature is measured and controlled with a type $\mathrm{K}$ thermocouple composed of thin, 0.1-mm-diameter wires of chromel and alumel, fusion-welded under argon gas to form a small bead. This bead is carefully positioned and spot-welded under argon at the center of the specimen.

As the grips are water-cooled, a parabolic temperature distribution will develop along the specimen. Previous studies ${ }^{[17,19]}$ have shown that the peak temperature remains reasonably uniform $\left(T= \pm 5{ }^{\circ} \mathrm{C}\right)$ in the central 2 to $3 \mathrm{~mm}$ of the sample at high temperatures between $500{ }^{\circ} \mathrm{C}$ and $1000{ }^{\circ} \mathrm{C}$, with the size of this region decreasing with increasing temperature. A consequence is that the majority of plastic deformation is localized in this central region.

Two different strain measurement techniques were used to account for this effect. The first is the method proposed by Roebuck, ${ }^{[4]}$ in which resistance is measured over the central 2 to $3 \mathrm{~mm}$ using two thin, spot-welded $\mathrm{Pt}-13 \mathrm{pctRh}$ wires. Changes in cross sectional area during testing lead to changes in resistance and in the voltage drop measured over the two wires. Roebuck showed that, assuming the test volume remains constant and neglecting elastic changes, plastic strain can be calculated as:

$$
\varepsilon_{\mathrm{p}}=\ln \sqrt{\left(R_{\mathrm{t}} / R_{s}\right)}
$$

where $R_{\mathrm{s}}$ and $R_{\mathrm{t}}$ are resistances before and during deformation.

The second approach measures strain by DIC. A fine speckle pattern is produced on one of the sample surfaces using high-temperature paint. The resulting pattern with many light, dark, and gray areas offers an ideal target for tracking. During testing, the specimen is illuminated by a bright, diffuse LED light source positioned behind an Allied Vision Technologies $\subset$ Manta G-146 ${ }^{\mathrm{TM}}$ camera which records the test. The camera has a resolution of 1.4 megapixels and offers a nominal frame rate of $17.8 \mathrm{fps}$ when the full field of view (FOV) of $1388 \times 1038$ pixels is monitored. Higher frame rates of up to around $50 \mathrm{fps}$ can be achieved when the full FOV is reduced to a smaller region of interest (ROI), which for the case of present tests measures around $250 \times 1000$ pixels. However, such high frame rates have been found to produce unnecessarily large amounts of data and offer little additional information at typical strain rates; hence, frame rates between 1 and $10 \mathrm{fps}$ were chosen.

The Imetrum Ltd@ Video Gauge ${ }^{\mathrm{TM}}$ software tool analyses images captured by the camera and applies proprietary sub-pixel pattern recognition algorithms to detect any changes occurring during testing in comparison to a reference state. Displacement and strain are measured and calculated in real time between user-defined target areas, in this case set $3 \mathrm{~mm}$ apart around the center of the specimen, with a strain resolution of around 20 microstrain. The target areas were chosen to be quadratic, with the side length corresponding to the width of the specimen. This choice was made as a compromise between improved strain accuracy provided by larger windows and increased spacial resolution 
provided by smaller ones. ${ }^{[23]}$ Finally, analogue signals for load, LVDT, or temperature channels are transmitted from the ETMT to the Video Gauge ${ }^{\mathrm{TM}}$ software through a Signal Interface Unit, thus allowing all relevant data to be collected and saved in one location, and averting potential issues of synchronizing data.

\section{Stepped-Temperature Testing (STT)}

Non-isothermal tensile tests-with the temperature being ramped at a constant rate after reaching the plastic regime-were carried out to deduce information regarding the variation of flow stress with temperature.

A schematic illustration of the method is given in Figure 4(a). Samples are first deformed isothermally at a constant initial temperature $T_{\mathrm{i}}$ of $500{ }^{\circ} \mathrm{C}$ or $750{ }^{\circ} \mathrm{C}$ and constant initial strain rates $\dot{\varepsilon}_{\text {i }}$ close to $2 \times 10^{-5}, 10^{-4}$, and $5 \times 10^{-4} / \mathrm{s}$. After reaching an initial plastic strain value $\varepsilon_{\mathrm{p}, \mathrm{i}}$ of $0.2,0.5$, or $1 \mathrm{pct}$, the temperature is ramped, at a constant rate $\dot{T}$ of $0.4,2$, and $10^{\circ} \mathrm{C} / \mathrm{s}$, respectively, up to $1150{ }^{\circ} \mathrm{C}$. The values of these temperature ramps were chosen in accordance with the three different strain rates to yield similar total levels of plastic deformation. In the case of tests between $500{ }^{\circ} \mathrm{C}$ and $1150{ }^{\circ} \mathrm{C}$, the durations of temperature ramps were 1625,325 , and 65 seconds, respectively. In each case, this corresponds

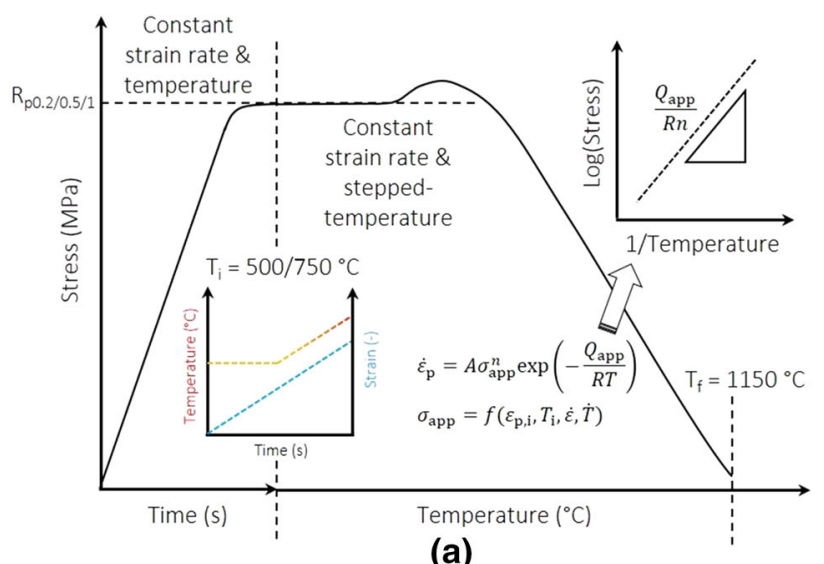

(a)

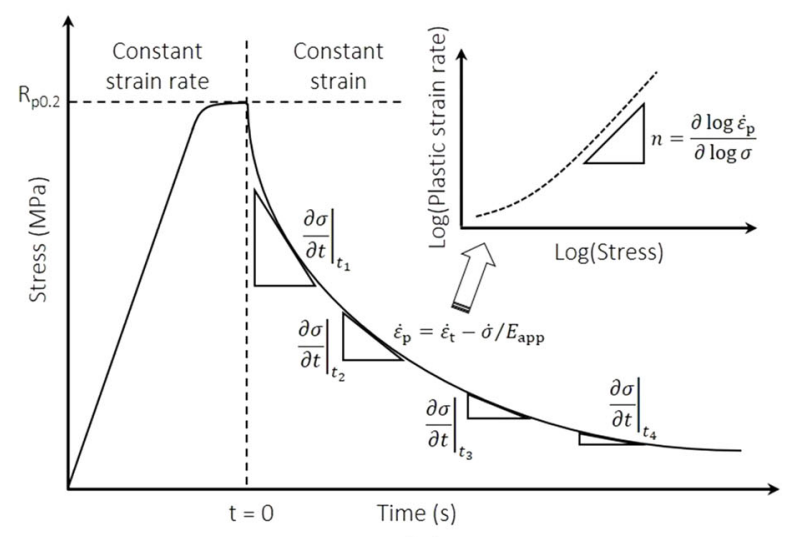

(b)

Fig. 4-Schematic ETMT test methodology for stepped-temperature testing and $(b)$ stress relaxation testing. to a total strain of around 3.25 pet during ramping. This value was chosen to be significantly lower than the total elongation observed in standard tensile tests. This implies that specimen necking can be disregarded and that the apparent flow stress can be calculated as engineering stress. The reason for repeating tests over two different temperature ranges, of $650{ }^{\circ} \mathrm{C}$ and $400{ }^{\circ} \mathrm{C}$, was to check whether the level of plastic hardening affects deformation behavior at higher temperatures.

As it is intended that the specimen continues to deform plastically at the prescribed strain rate during temperature ramping, crosshead speed must be compensated to also account for thermal expansion effects in accordance with:

$$
\dot{\varepsilon}_{\mathrm{t}}=\dot{\varepsilon}_{\text {mechanical }}+\dot{\varepsilon}_{\text {thermal }} .
$$

Here $\dot{\varepsilon}_{\mathrm{t}}$ is the total strain rate measured for the specimen, $\dot{\varepsilon}_{\text {mechanical }}$ is the strain rate component resulting from the constant crosshead displacement, and $\dot{\varepsilon}_{\text {thermal }}$ is the additional strain rate due to thermal expansion and changes in $\gamma^{\prime}$ volume fraction. $\dot{\varepsilon}_{\text {thermal }}$ was measured for each testing condition in a separate stepped-temperature test at zero load and $\dot{\varepsilon}_{\text {mechanical }}$ was adjusted accordingly to yield the desired total strain rate.

All testing conditions for STT are summarized in Table II.

\section{Stress Relaxation Testing (SRT)}

Isothermal stress relaxation tests were performed between $650{ }^{\circ} \mathrm{C}$ and $1050{ }^{\circ} \mathrm{C}$ at intervals of $100{ }^{\circ} \mathrm{C}$ using the method shown in Figure 4(b) to deduce information on creep performance. Specimens are deformed at a constant initial strain rate of approximately $10^{-4} / \mathrm{s}$ until a predefined plastic strain level of 0.2 pct was reached. This value was chosen following ${ }^{[24]}$ in order to achieve steady-state stress behavior and to provide a measure of the current creep strength of the alloy. Crosshead displacement is then stopped and held in that exact position under LVDT control. Load relaxation is measured over a period $t_{\mathrm{R}}$ of 20 hours, again following. ${ }^{[24]}$ Considering the much longer test durations compared to tensile tests or stepped-temperature tests, a larger specimen cross section of $2 \times 2 \mathrm{~mm}^{2}$ was chosen to ensure that oxidation would not affect mechanical properties. Values for specimen width/thickness were chosen based on the extensive experimental and modeling work on creep and oxidation damage in thin-walled specimens. ${ }^{[25-27]}$

Comparison tests were carried out for the $\langle 001\rangle$ direction on cylindrical specimens of $6 \mathrm{~mm}$ gauge length and $3 \mathrm{~mm}$ diameter using an Instron (C) Electropuls ${ }^{\mathrm{TM}}$ E10000 linear-torsion all-electric system. This testing rig is equipped with a split furnace controlled using a type $\mathrm{K}$ thermocouple positioned close to the specimen gauge. For both systems, the DIC method was used to measure strain.

Testing conditions employed for SRT are summarized in Table III. 
Table II. Summary of Stepped-Temperature Tests Carried Out on the ETMT System

\begin{tabular}{|c|c|c|c|c|c|c|c|c|c|c|c|c|c|c|}
\hline \multirow[b]{2}{*}{$\begin{array}{l}\text { Test } \\
\text { System }\end{array}$} & \multirow[b]{2}{*}{$\begin{array}{l}\text { Specimen } \\
\text { Cross Section }\end{array}$} & \multirow[b]{2}{*}{$\begin{array}{l}\text { Heating } \\
\text { Method }\end{array}$} & \multirow[b]{2}{*}{$\begin{array}{l}\text { Strain Measure- } \\
\text { ment Method }\end{array}$} & \multicolumn{2}{|c|}{$\Delta T\left({ }^{\circ} \mathrm{C}\right)$} & \multicolumn{3}{|c|}{$\dot{T}\left({ }^{\circ} \mathrm{C} / \mathrm{s}\right)$} & \multicolumn{3}{|c|}{$\dot{\varepsilon}\left(\mathrm{s}^{-1}\right)$} & \multicolumn{3}{|c|}{$\varepsilon_{\mathrm{p}, \mathrm{i}}(\mathrm{Pct})$} \\
\hline & & & & $\begin{array}{l}500 \text { to } \\
1150\end{array}$ & $\begin{array}{c}750 \text { to } \\
1150\end{array}$ & 0.4 & 2 & 10 & $2 \times 10^{-5}$ & $10^{-4}$ & $5 \times 10^{-4}$ & 0.2 & 0.5 & 1 \\
\hline Instron $\subset$ & $1 \times 1.1 \mathrm{~mm}^{2}$ & Joule & DIC & $\mathrm{x}$ & & $\mathrm{x}$ & & & $\mathrm{x}$ & & & $\mathrm{X}$ & & \\
\hline \multirow[t]{7}{*}{ ETMT } & & heating & & $\mathrm{x}$ & & & $\mathrm{x}$ & & & $\mathrm{x}$ & & $\mathrm{x}$ & & \\
\hline & & & & $\mathrm{x}$ & & & & $\mathrm{x}$ & & & $\mathrm{x}$ & $\mathrm{x}$ & & \\
\hline & & & & & $\mathrm{x}$ & $\mathrm{X}$ & & & $\mathrm{x}$ & & & $\mathrm{X}$ & & \\
\hline & & & & & $\mathrm{x}$ & & $\mathrm{x}$ & & & $\mathrm{x}$ & & $\mathrm{X}$ & & \\
\hline & & & & & $\mathrm{x}$ & & & $\mathrm{x}$ & & & $\mathrm{x}$ & $\mathrm{X}$ & & \\
\hline & & & & $\mathrm{x}$ & & & $\mathrm{x}$ & & & $\mathrm{x}$ & & & $\mathrm{x}$ & \\
\hline & & & & $\mathrm{x}$ & & & $\mathrm{x}$ & & & $\mathrm{x}$ & & & & $\mathrm{x}$ \\
\hline
\end{tabular}

\section{E. Verification Testing}

A limited number of tensile tests was carried out on each crystallographic orientation for verification purposes and to prove the reliability of the new testing system, as summarized in Table IV. Benchmark tests on the Instron $($ C ETMT were performed on samples of $1 \times 1.1 \mathrm{~mm}^{2}$ cross section at $500{ }^{\circ} \mathrm{C}$ and an initial strain rate close to $10^{-5} / \mathrm{s}$, and at $750{ }^{\circ} \mathrm{C}$ and initial strain rates of $10^{-5}, 10^{-4}$, and $10^{-2} / \mathrm{s}$. LVDT control was used at constant crosshead displacement rates.

Comparison tests were performed under similar conditions at NPL using an in-house ETMT system. As this system lacks an LVDT sensor for displacement control, tests were carried out at constant loading rates of $0.4,2$, and $10 \mathrm{~N} / \mathrm{s}$, which came close to replicating the constant displacement rate conditions.

Finally, further comparison tests at $750{ }^{\circ} \mathrm{C}$ were carried out using regular, cylindrical testpieces of $6 \mathrm{~mm}$ gauge length and $3 \mathrm{~mm}$ diameter using an Instron (c) 8862 servo-electric system. In this case, high temperature was achieved with a split furnace arrangement and was controlled with a type $\mathrm{K}$ thermocouple positioned close to the specimen gauge. With regards to strain measurement, the DIC method was used for all tests on the Instron (c) ETMT and the 8862 servo-electric systems. For tests on the NPL ETMT, plastic strain was calculated from resistance measurements, as described in Eq. [1]. The elastic strain component was added separately using temperature-dependent values for the elastic moduli, $E(T)$, calculated from high-temperature dynamic resonance measurements carried out for each individual orientation at NPL. For further details regarding this procedure, the interested reader is directed to References 28 through 30.

\section{RESULTS}

\section{A. Verification Tests}

Tensile curves at $500{ }^{\circ} \mathrm{C}$ are shown in Figure 5; comparison is made with duplicate tests on the NPL ETMT system. Results from both ETMT systems are in good agreement for all orientations, but values of engineering stress in the plastic regime for the $\langle 011\rangle$ and $\langle 111\rangle$ directions are slightly higher in the NPL tests. This could be related to the higher strain rate of around $10^{-4} / \mathrm{s}$ corresponding to the chosen constant loading rate of $2 \mathrm{~N} / \mathrm{s}$, as opposed to a strain rate of $10^{-5} / \mathrm{s}$ in Instron $(\mathrm{ETMT}$ tests. However, similar experiments on alloy CMSX-4 showed that the influence of strain rate only becomes significant above $700{ }^{\circ} \mathrm{C}$ and justified differences in flow stress with changes in the off-axis deviation of the test specimens. ${ }^{[31]}$ Considering that specimens in the present study were manufactured from distinct bars and that cross section measurements were carried out independently, discrepancies caused by crystal orientation and sample dimensions cannot be ruled out.

Similarly good agreement is found in tests at $750{ }^{\circ} \mathrm{C}$ across all testing conditions, as illustrated in Figure 6(a) through (f). Agreement is best at intermediate strain rates of $10^{-4} / \mathrm{s}$, regardless of crystal orientation. At $10^{-5} / \mathrm{s}$, tests on the Instron $\odot$ ETMT exhibit lower engineering stress values, likely due to effects of oxidation over longer testing periods. Oxidation damage in thin-walled specimens is characterized by both (1) a reduction in load-bearing cross section through the formation of a continuous oxide scale and a $\gamma^{\prime}$ denuded zone near the surface, and (2) changes in $\gamma^{\prime}$ volume fraction and chemical concentration profiles within the substrate. ${ }^{[26]}$ On the one hand, this highlights the importance of taking into account environmental damage and of carrying out small-scale tests at low strain rates in a protective argon atmosphere if they are to be compared directly with standard tests. ${ }^{[19]}$ On the other hand, this also proves the usefulness of miniaturized ETMT testing for replicating service conditions experienced by thin-walled turbine blade sections. For rapid tests at $10^{-2} / \mathrm{s}$, verification tests on the 8862 servo-electric system yield higher stress values than ETMT tests in the $\langle 001\rangle$ and $\langle 111\rangle$ directions.

\section{B. Stepped-Temperature Tests}

The variation of proof stress with temperature is illustrated as a function of orientation in Figure 7(a) through (f) and as a function of deformation rate in Figure 8(a) through (f). The ramping step was started after reaching an initial plastic strain of 0.2 pct at (1) 
Table III. Summary of Stress Relaxation Tests Carried Out on the ETMT and the E10000 Systems

\begin{tabular}{|c|c|c|c|c|c|c|c|c|c|c|c|}
\hline \multirow[b]{2}{*}{ Test System } & \multirow{2}{*}{$\begin{array}{l}\text { Specimen } \\
\text { Cross Section } \\
\left(\mathrm{mm}^{2}\right)\end{array}$} & \multirow[b]{2}{*}{ Heating Method } & \multirow{2}{*}{$\begin{array}{l}\text { Strain } \\
\text { Meas. } \\
\text { Method }\end{array}$} & \multicolumn{5}{|c|}{$T\left({ }^{\circ} \mathrm{C}\right)$} & \multirow{2}{*}{$\begin{array}{c}\dot{\varepsilon}\left(\mathrm{s}^{-1}\right) \\
10^{-4}\end{array}$} & \multirow[b]{2}{*}{$\begin{array}{c}\varepsilon_{\mathrm{p}, \mathrm{i}}(\mathrm{Pct}) \\
0.2\end{array}$} & \multirow[b]{2}{*}{$\begin{array}{c}t_{\mathrm{R}}(\mathrm{h}) \\
20\end{array}$} \\
\hline & & & & 650 & 750 & 850 & 950 & 1050 & & & \\
\hline Instron $\subset$ ETMT & $2 \times 2$ & Joule heating & $\mathrm{DIC}$ & $\mathrm{x}$ & $\mathrm{x}$ & $\mathrm{x}$ & $\mathrm{x}$ & $\mathrm{x}$ & $\mathrm{x}$ & $\mathrm{x}$ & $\mathrm{x}$ \\
\hline Instron $\subset \mathrm{E} 10000$ & 7.1 & Furnace & $\mathrm{DIC}$ & & $\mathrm{x}$ & $\mathrm{x}$ & & & $\mathrm{x}$ & $\mathrm{x}$ & $\mathrm{x}$ \\
\hline
\end{tabular}

Table IV. Summary of Tensile Tests Carried Out on the NPL and the Instron $₫$ ETMT Systems as well as on the 8862 Servo-Electric System

\begin{tabular}{|c|c|c|c|c|c|c|c|c|}
\hline \multirow[b]{2}{*}{ Test System } & \multirow{2}{*}{$\begin{array}{l}\text { Specimen } \\
\text { Cross Section } \\
\left(\mathrm{mm}^{2}\right)\end{array}$} & \multirow[b]{2}{*}{ Heating Method } & \multirow{2}{*}{$\begin{array}{l}\text { Strain } \\
\text { Measurement } \\
\text { Method }\end{array}$} & \multicolumn{2}{|c|}{$T\left({ }^{\circ} \mathrm{C}\right)$} & \multicolumn{3}{|c|}{$\dot{\varepsilon}\left(\mathrm{s}^{-1}\right)$} \\
\hline & & & & 500 & 750 & $10^{-5}$ & $10^{-4}$ & $10^{-3}$ \\
\hline Instron $@$ ETMT & $1 \times 1.1$ & Joule heating & DIC & $\mathrm{x}$ & & $\mathrm{x}$ & & \\
\hline NPL ETMT & $1 \times 1$ & Joule heating & Resistance & $\mathrm{x}$ & $\mathrm{x}$ & $\mathrm{x}$ & $\begin{array}{l}\mathrm{X} \\
\mathrm{X}\end{array}$ & $\mathrm{x}$ \\
\hline Instron@ $\subset 8862$ & 7.1 & Furnace & $\mathrm{DIC}$ & & $\begin{array}{l}\mathrm{x} \\
\mathrm{x}\end{array}$ & $\begin{array}{l}\mathrm{x} \\
\mathrm{X}\end{array}$ & $\begin{array}{l}x \\
X\end{array}$ & $\begin{array}{l}\mathrm{x} \\
\mathrm{X}\end{array}$ \\
\hline
\end{tabular}

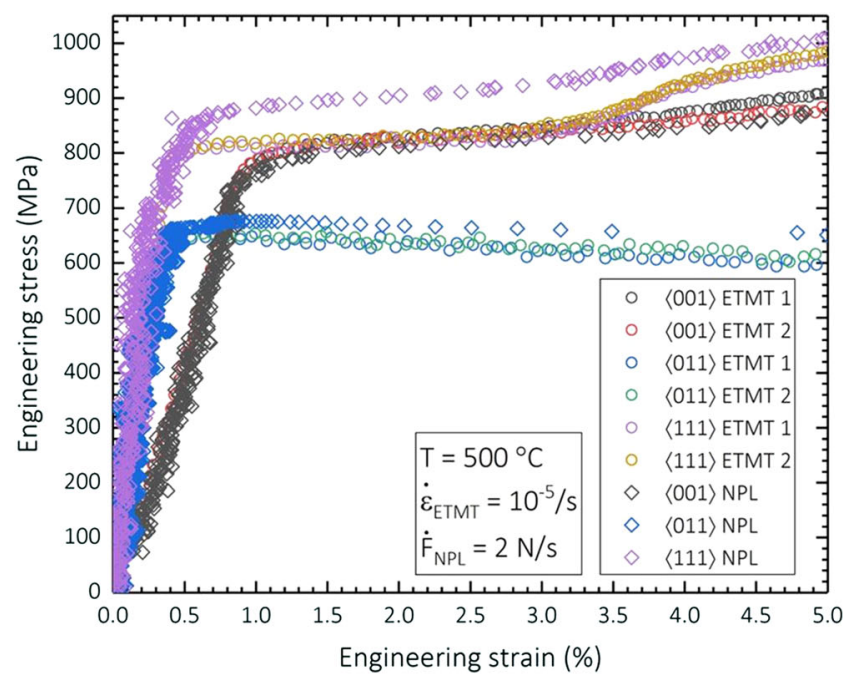

(a)

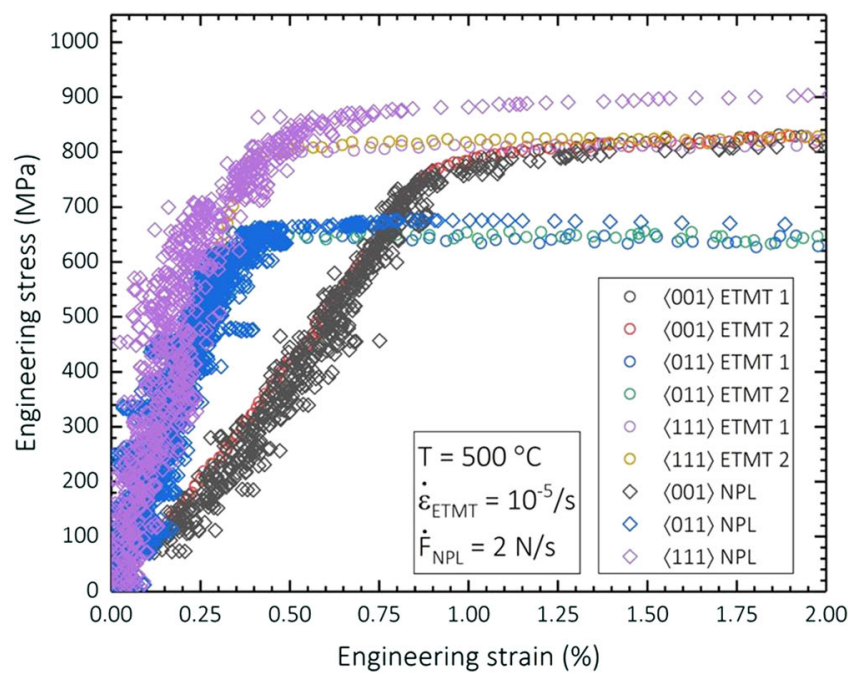

(b)

Fig. 5-Tensile test results at $500{ }^{\circ} \mathrm{C}$ from the Instron $\odot$ ETMT and the NPL ETMT. Results are plotted up to $(a) 5$ pct engineering strain to provide an overview of the test and $(b) 2$ pct engineering strain to provide a more detailed view of the elastic regime and initial yielding.

$500{ }^{\circ} \mathrm{C}$ and (2) $750{ }^{\circ} \mathrm{C}$, in order to compare the effects of prior deformation at lower temperatures on the anomalous yielding effect. One can see that, for all orientations, a peak in the proof stress occurs in the range of $750{ }^{\circ} \mathrm{C}$ to $800{ }^{\circ} \mathrm{C}$. This is in accordance with the results of Shah and Duhl ${ }^{[32]}$ for PWA1480, of Miner et al. ${ }^{[33,34]}$ for René N4, and of Allan ${ }^{[35]}$ and Bullough et al. ${ }^{[31]}$ for CMSX-4.

Several points emerge from the results presented in Figures 7 and 8 . First, the proof stress is not influenced by strain rate by strain rate and/or temperature ramping rate until a peak stress has been reached, in agreement with previous experimental and modeling work. ${ }^{[31,36-38]}$ In this anomalous yielding regime, cross-slip of short dislocation segments from $\{111\}$ to $\{001\}$ glide planes-leading to either small Paidar-Pope-Vitek locks or large Kear-Wilsdorf locks ${ }^{[39,40]}$ _is operative. Such cross-slip events are promoted by the anisotropy of both APB energy and elastic properties along the $\{111\}$ and $\{001\}$ planes.

Second, once material strength decreases above $750{ }^{\circ} \mathrm{C}$, higher strength at larger strain rates is consistently observed, in accordance with time-dependent plasticity. The initial decline in proof stress has been commonly related to slip activation on the cube plane by $a / 2\langle 110\rangle$ pairs and, at higher temperatures, by perfect $a[100]$ single dislocations. ${ }^{[0]}$ Recent studies have identified diffusion-activated plasticity as an additional operating mechanism which could explain the decreasing strength in this temperature regime. ${ }^{[41,42]} \mathrm{A}$ further significant weakening effect at higher temperatures is a 


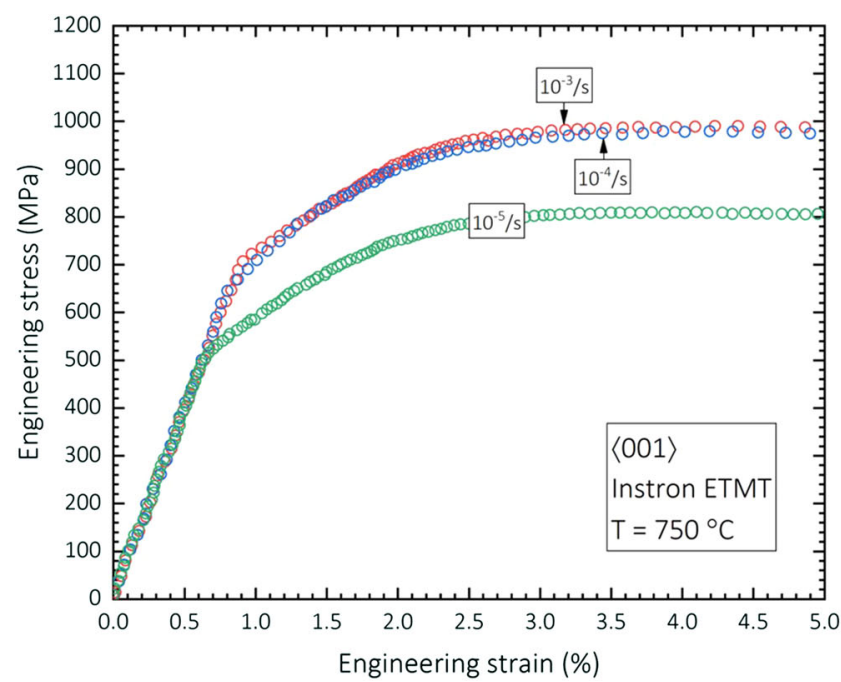

(a)

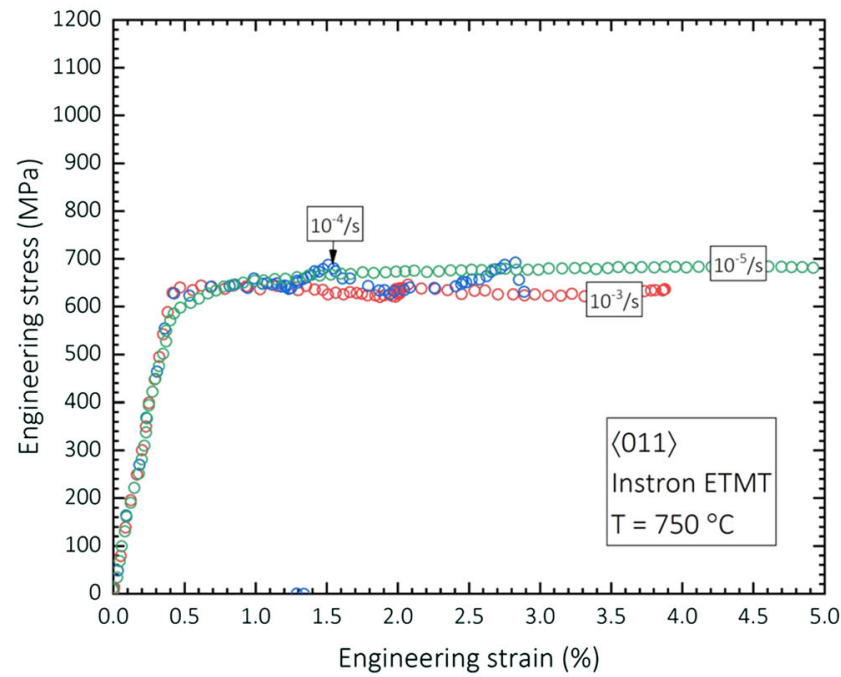

(c)

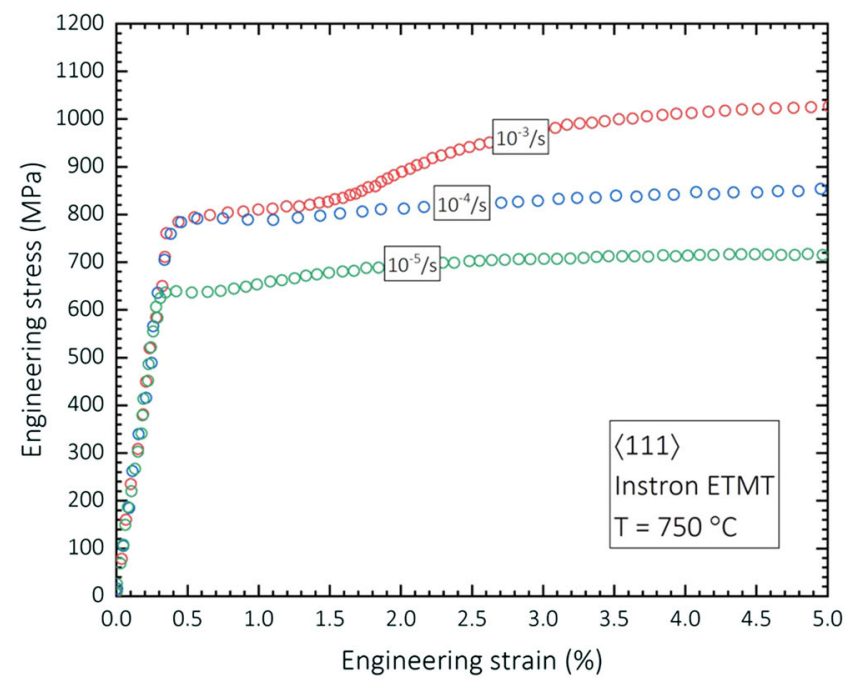

(e)

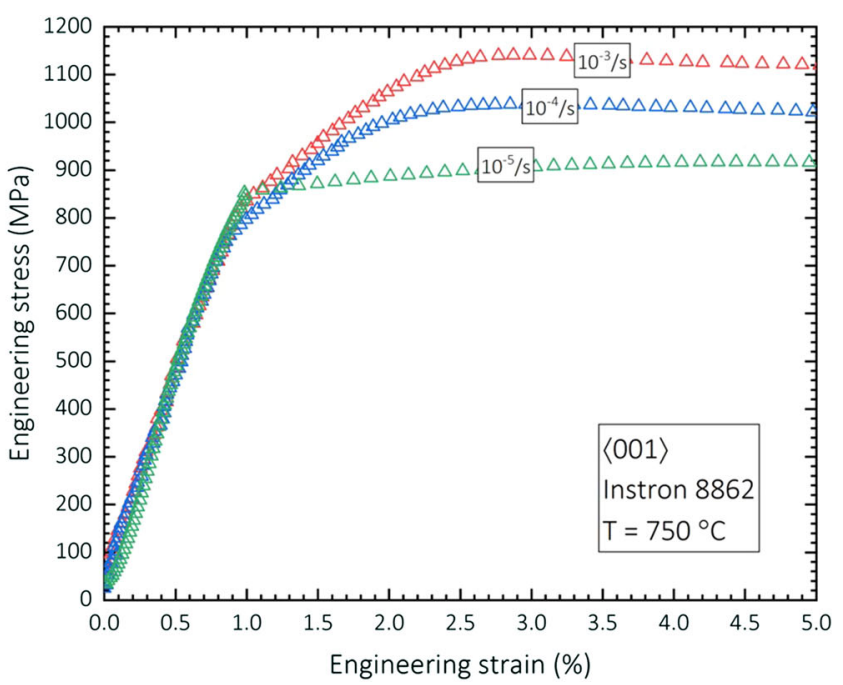

(b)

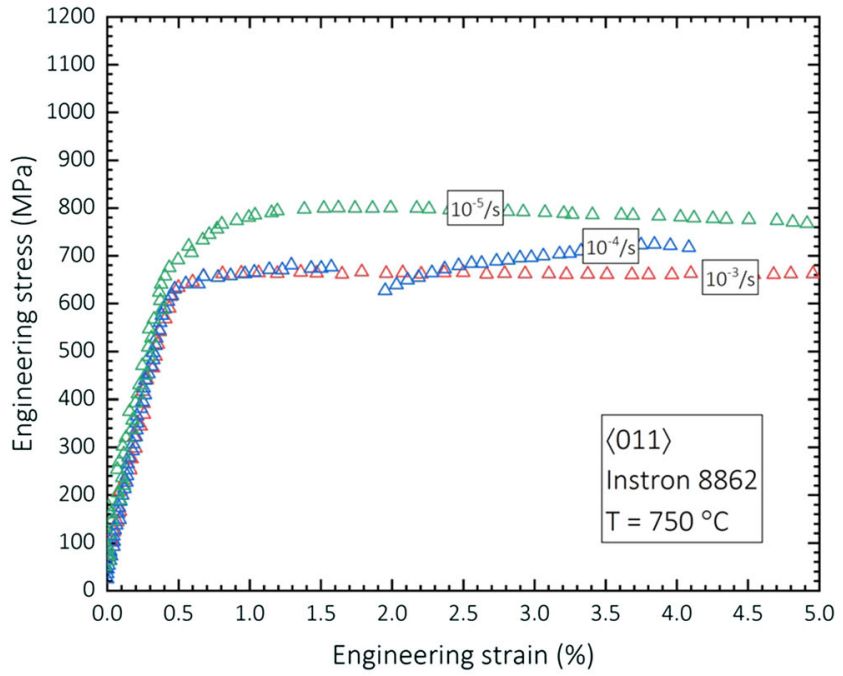

(d)

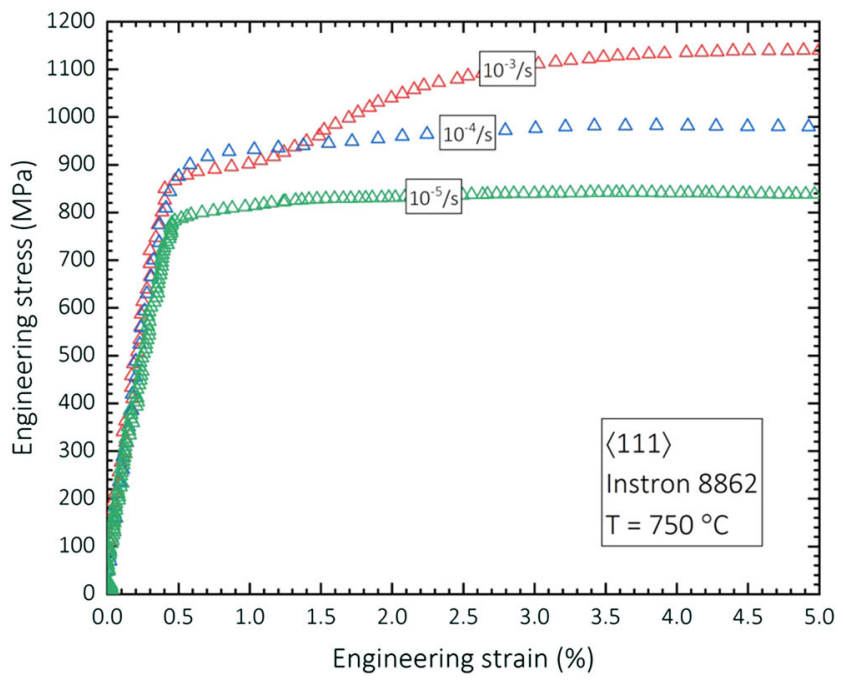

(f)

Fig. 6 - Tensile test results at $750{ }^{\circ} \mathrm{C}$ from the Instron $\odot$ ETMT and 8862 servo-electric systems presented for the $(a$ and $b)\langle 001\rangle$ direction, $(c$ and $d)\langle 011\rangle$ direction, and $(e$ and $f)\langle 111\rangle$ direction. 


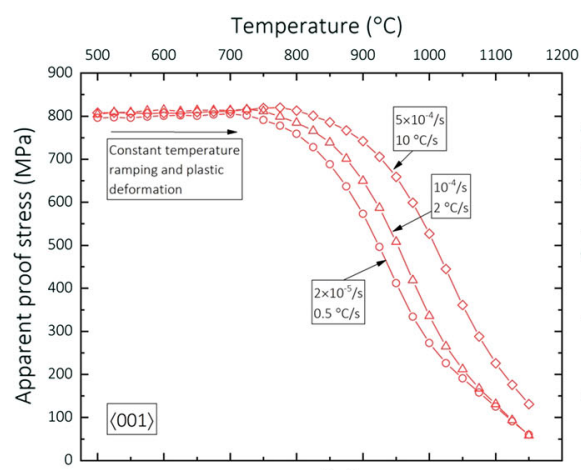

(a)

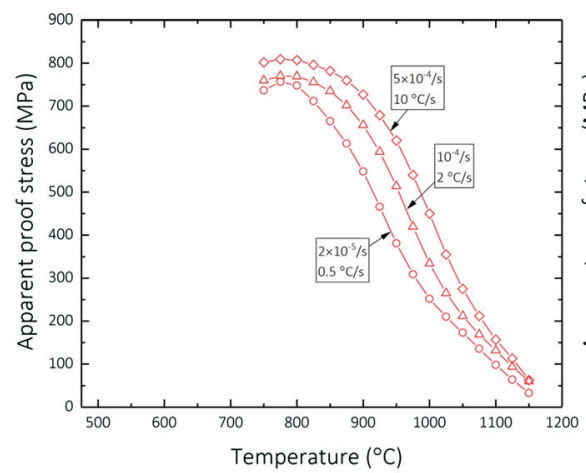

(d)

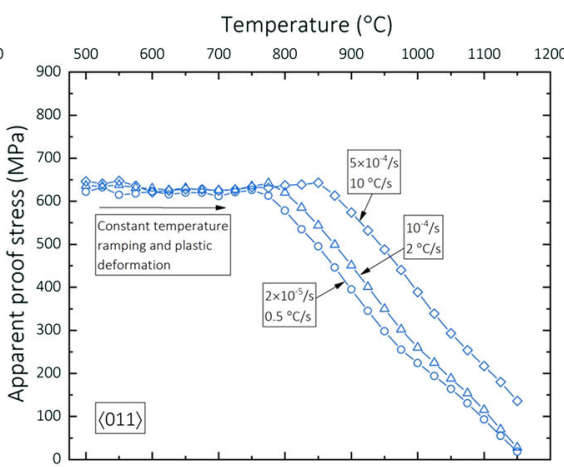

(b)

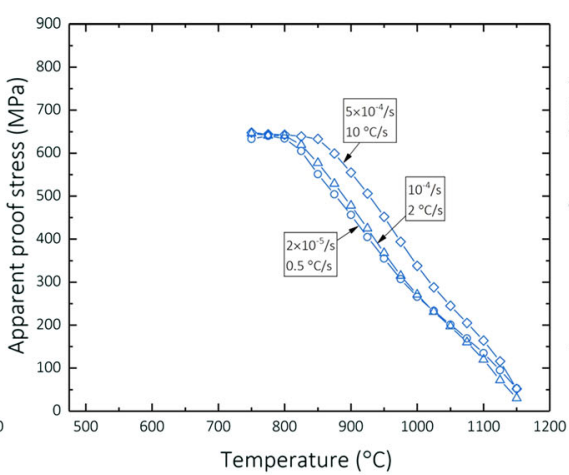

(e)

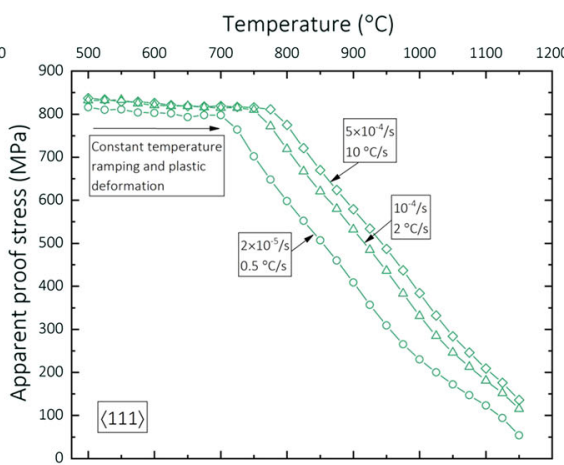

(c)

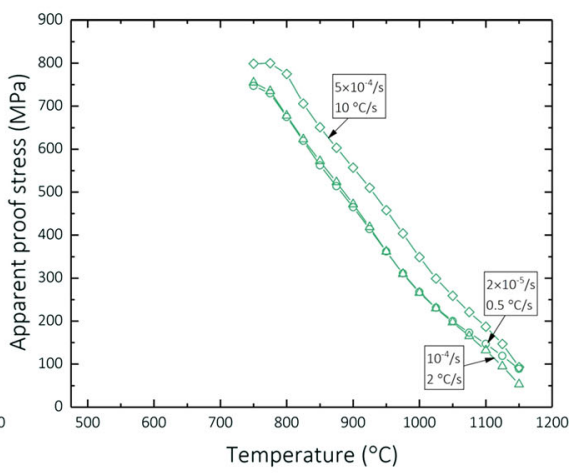

(f)

Fig. 7-STT results for single-crystal specimens with $(a$ and $d)\langle 001\rangle$ orientation, $(b$ and $e)\langle 011\rangle$ orientation, and $(c$ and $f)\langle 111\rangle$ orientation.

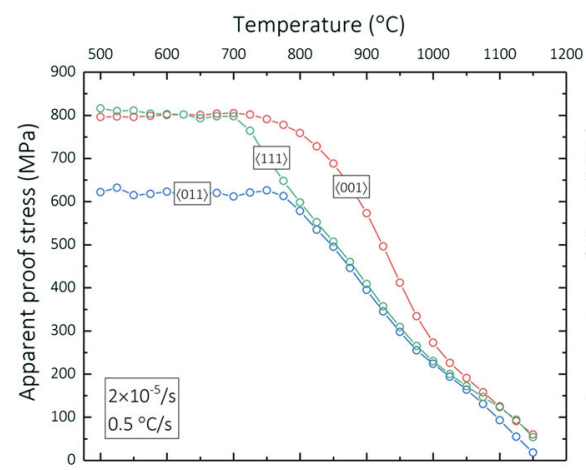

(a)

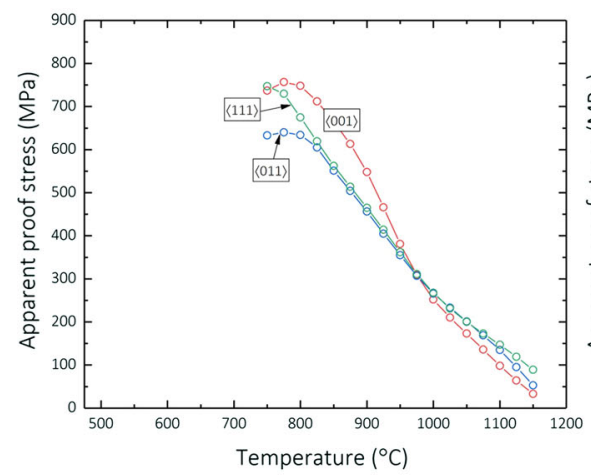

(d)

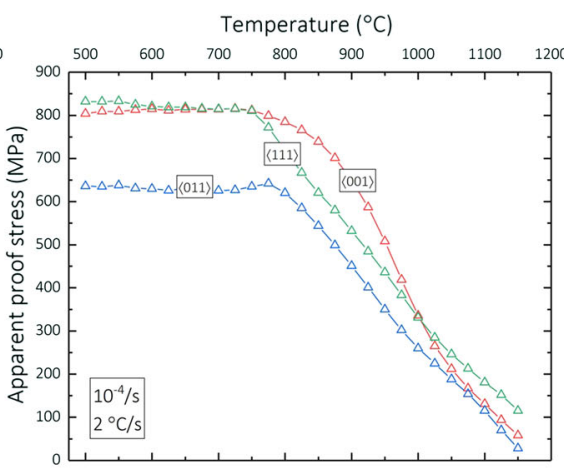

(b)

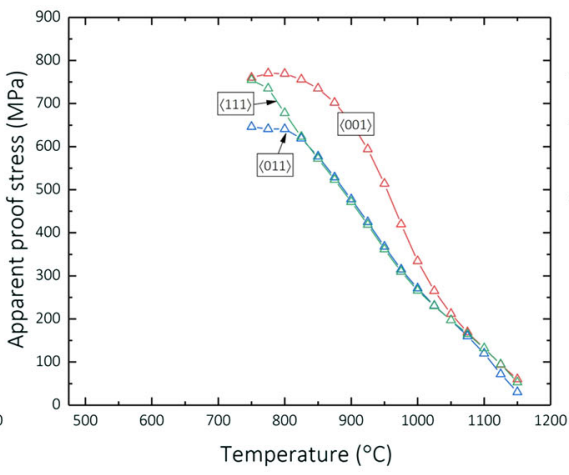

(e)

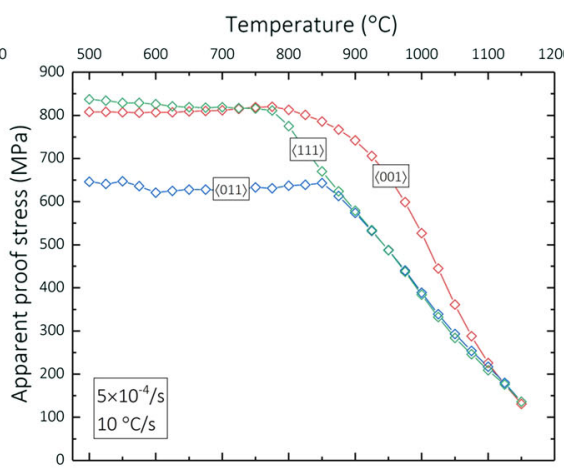

(c)

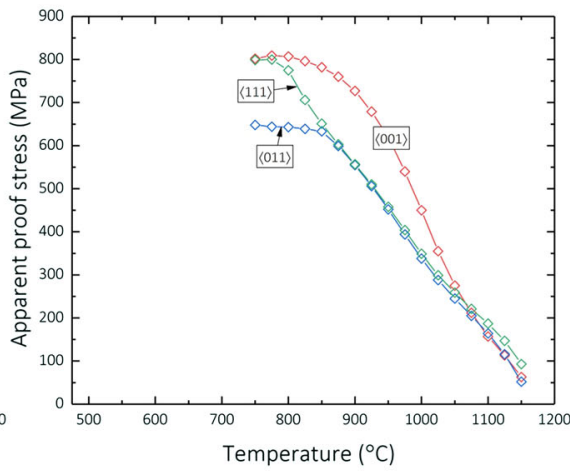

(f)

Fig. 8-STT results for tests carried out at initial strain rates of $(a$ and $b) 2 \times 10^{-5} / \mathrm{s},(c$ and $d) 10^{-5} / \mathrm{s}$, and $(e$ and $f) 5 \times 10^{-4} / \mathrm{s}$. 


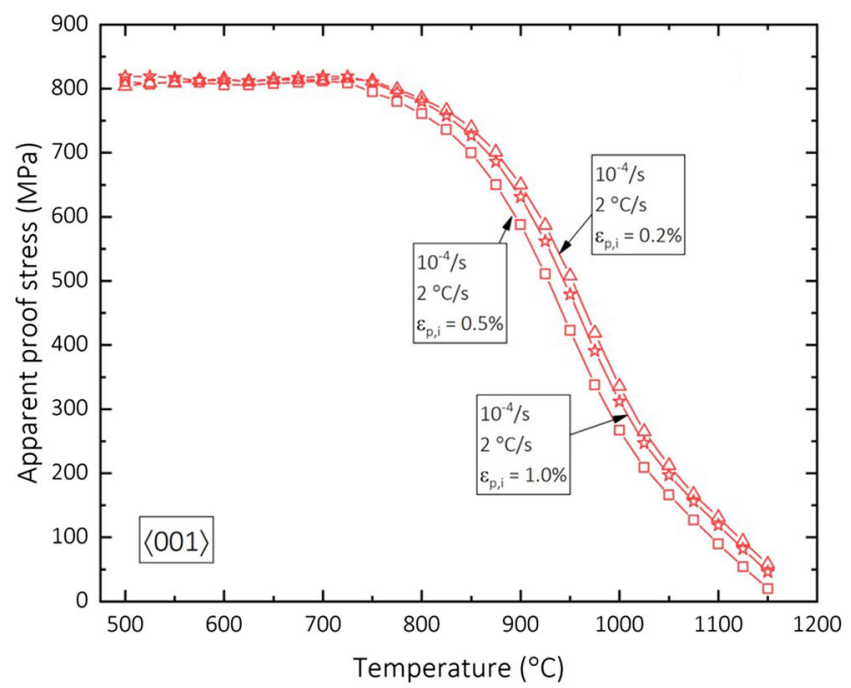

(a)

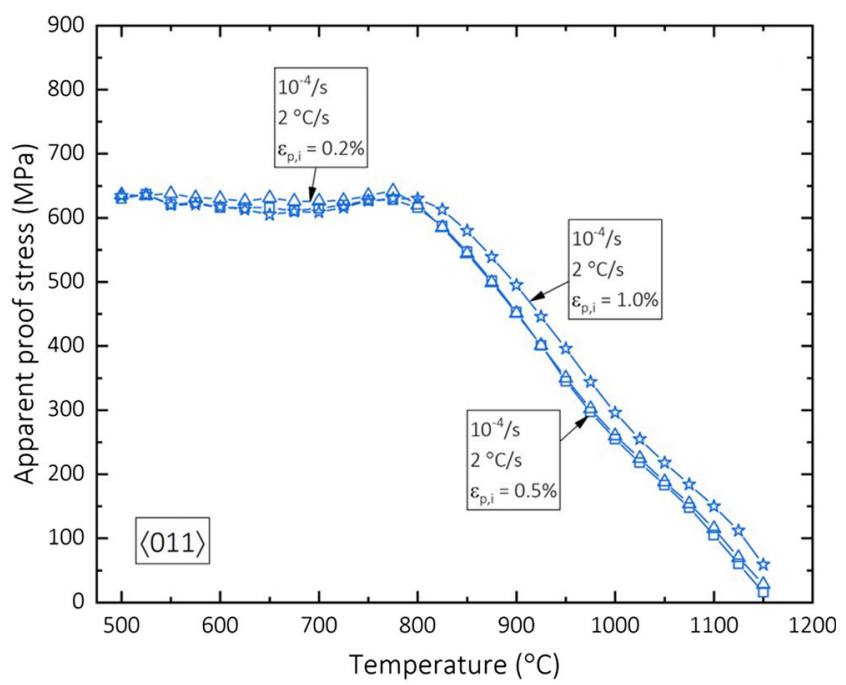

(b)

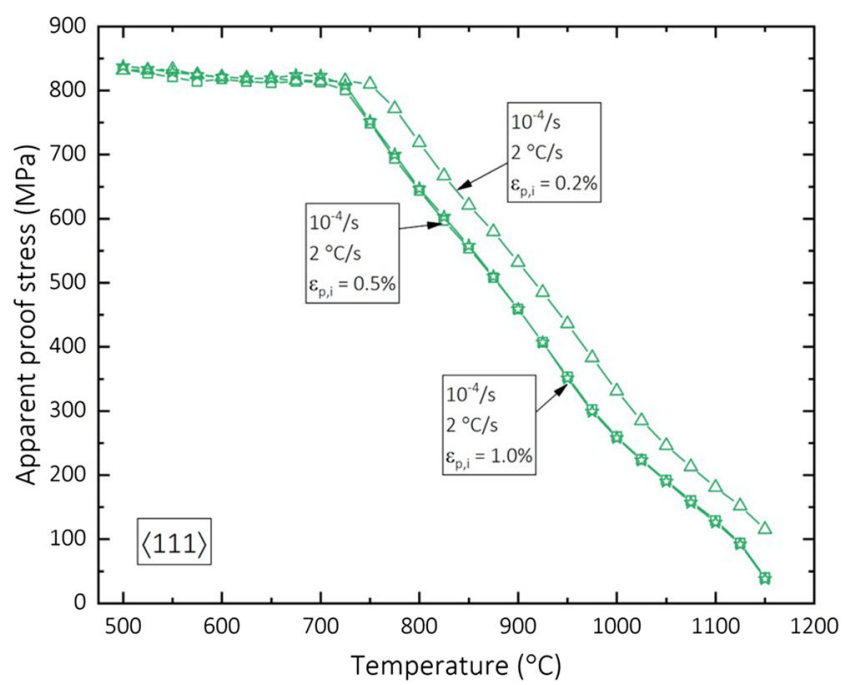

(c)

Fig. 9-STT results from tests in which the temperature-ramping step was started after varying initial plastic strain levels of $0.2,0.5$, and 1 pct. Results are shown separately for the $(a)\langle 001\rangle$ direction, $(b)\langle 011\rangle$ direction, and $(c)\langle 111\rangle$ direction.

decrease in $\gamma^{\prime}$ volume fraction, $\phi_{\mathrm{p}}$. Calculations using Thermo-Calc and the TTNi8 Ni-alloy database predict a decrease from 58 pct at $600{ }^{\circ} \mathrm{C}$ to nearly 0 pct at $1150{ }^{\circ} \mathrm{C}$ (see Figure 13(d)). Maximum precipitate strength is approximated to scale with the square root of $\phi_{\mathrm{p}}{ }^{[43]}$ thus explaining this pronounced drop.

For all tests - and regardless of strain rate-the strength on the $\langle 011\rangle$ direction is much lower until temperatures of $1000{ }^{\circ} \mathrm{C}$ and above are reached, at which point all orientations exhibit similar proof stress values. This observation is of particular interest, as previous studies ${ }^{[31,32,35]}$ reported that yield strength above $750{ }^{\circ} \mathrm{C}$ consistently increases from the $\langle 111\rangle$ to the $\langle 011\rangle$, and finally to the $\langle 001\rangle$ orientation. While $\langle 001\rangle$ remains the direction with highest strength for the SIT superalloy, there is now a discrepancy between the $\langle 011\rangle$ and $\langle 111\rangle$ directions. Proof stress values converge above $800{ }^{\circ} \mathrm{C}$, but, at lower temperatures, the $\langle 111\rangle$ direction is much stronger than $\langle 011\rangle$ and even surpasses $\langle 001\rangle$ below $600{ }^{\circ} \mathrm{C}$.

Third, the results are nearly identical regardless of whether temperature ramping was initiated at $500^{\circ} \mathrm{C}$ or at $750{ }^{\circ} \mathrm{C}$, thus suggesting that the degree of strain hardening imposed at lower temperatures does not substantially alter the estimate of the flow stress. However, to study the influence of the magnitude of pre-straining on the measured proof stress in greater detail, tests at an initial constant temperature of $500{ }^{\circ} \mathrm{C}$ were repeated while varying the plastic strain level before ramping to 0.5 and 1 pct. As shown in Figure 9(a) through (c), very little effect on proof stress was observed in the plateau region, in agreement with previous reports. ${ }^{[31,36-38]}$ In the high-temperature regime, the influence of initial plastic strain and of the 


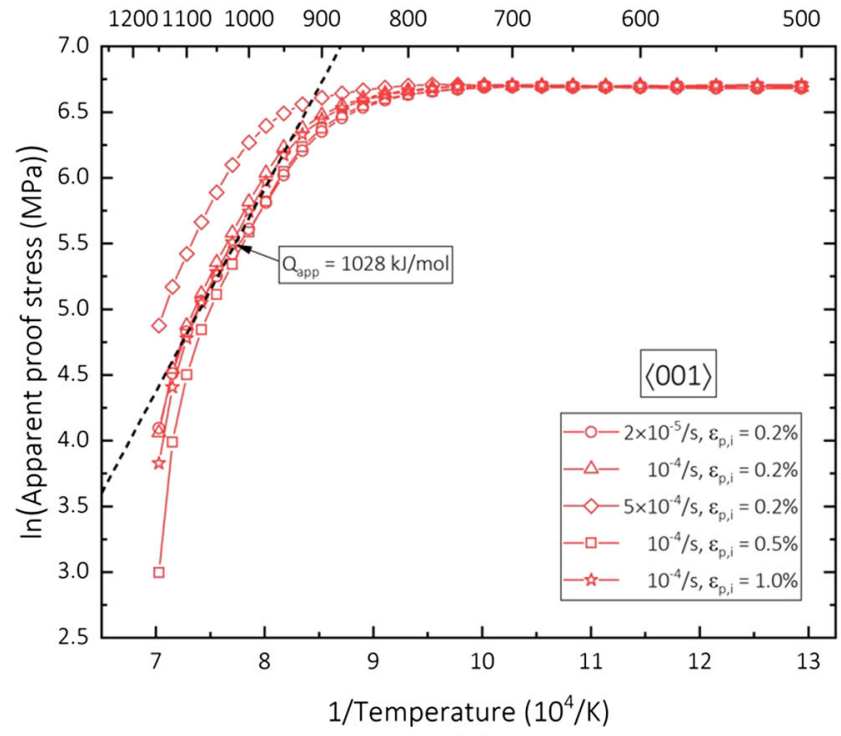

(a)

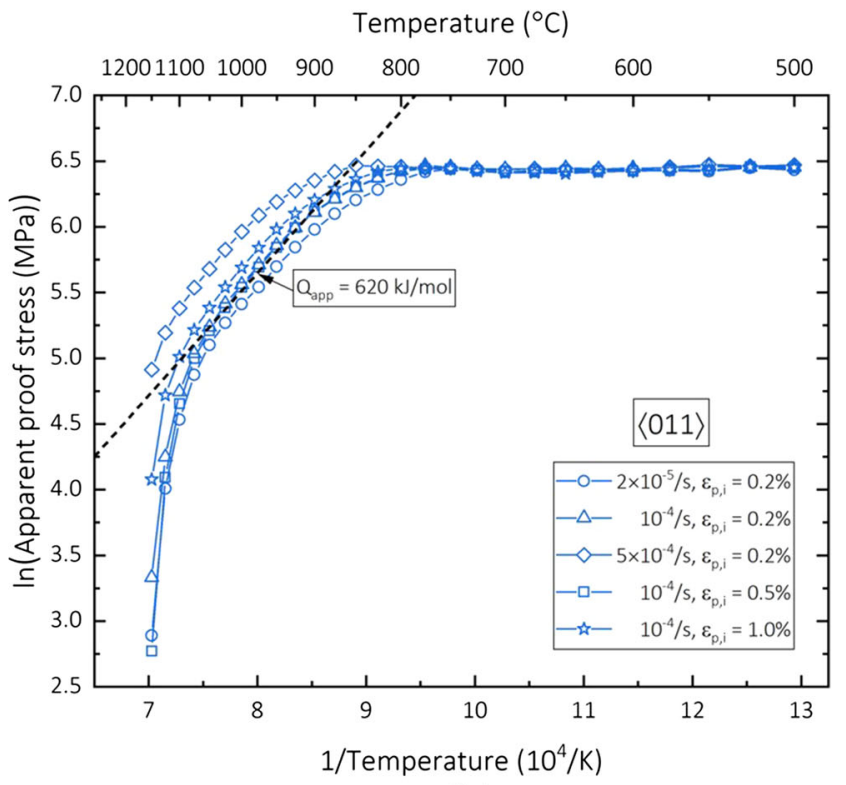

(b)

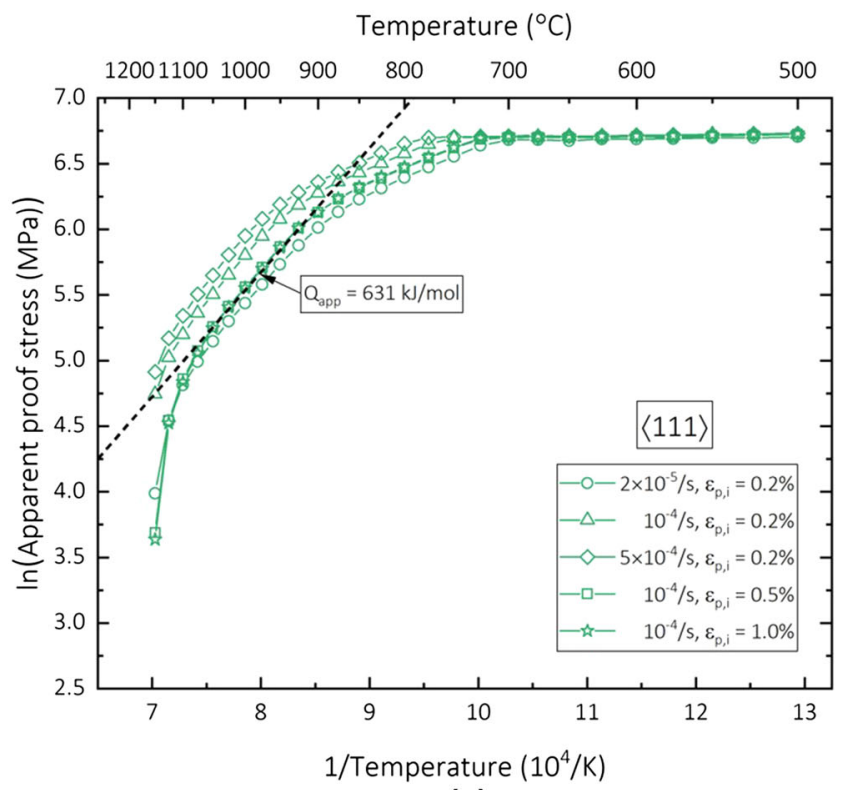

(c)

Fig. 10-Apparent activation energies extracted from STT between $500{ }^{\circ} \mathrm{C}$ and $1150{ }^{\circ} \mathrm{C}$ for the $(a)\langle 001\rangle$ direction, $(b)\langle 011\rangle$ direction, and $(c)$ $\langle 111\rangle$ direction. Estimates were extracted by fitting the dashed lines to experimental data from lower strain rate tests.

accumulated total strain level is unclear and there are differences in the responses of the three orientations. While for $\langle 001\rangle$ and $\langle 111\rangle$ the strength decreases with increasing initial strain, for $\langle 011\rangle$ the results are almost identical for initial plastic strain levels of 0.2 and 0.5 pct, and the strength is higher above $800{ }^{\circ} \mathrm{C}$ in the specimen pre-strained up to 1 pct. It can be concluded that, if a fair comparison is to be made, the level of pre-straining must be carefully controlled and maintained constant across all tests.
Finally, it has been found that the STT curves can be analyzed at temperatures beyond those associated with a maximum in the flow stress to extract an estimate of apparent activation energy, as shown schematically in Figure 4(a). For this, it is assumed that deformation rates of $2 \times 10^{-5}$ and $10^{-4} / \mathrm{s}$ are slow enough for a steady-state condition to be approached at each temperature level during the ramping segment. Estimates of the steady-state creep rate, $\dot{\varepsilon}_{\mathrm{s}}$, can then be expressed as: 


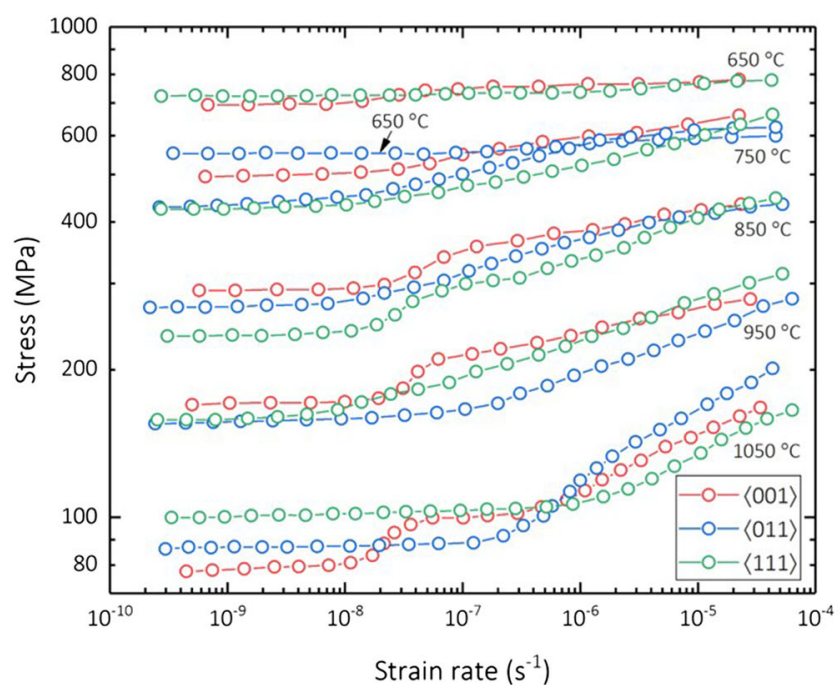

(a)

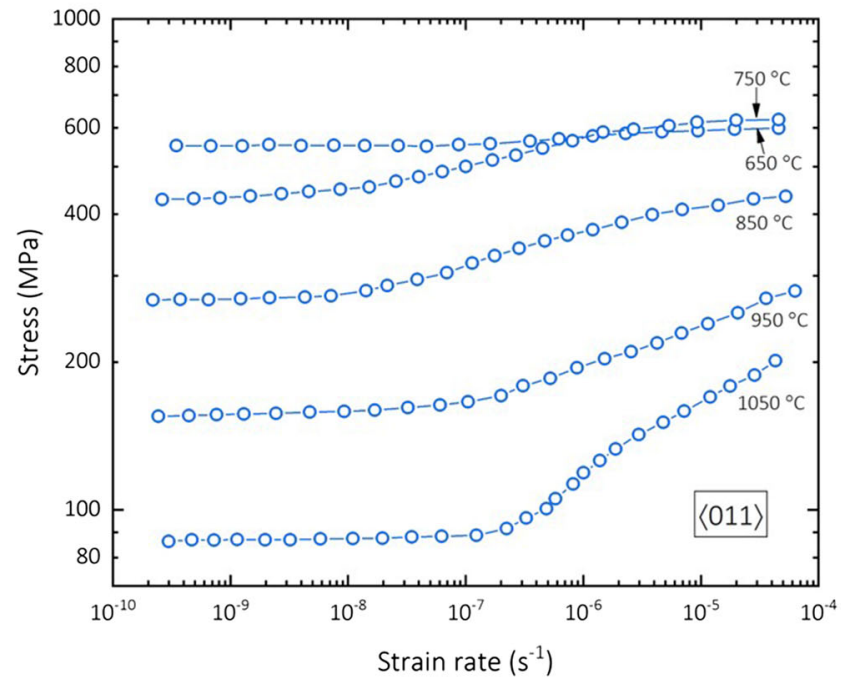

(c)

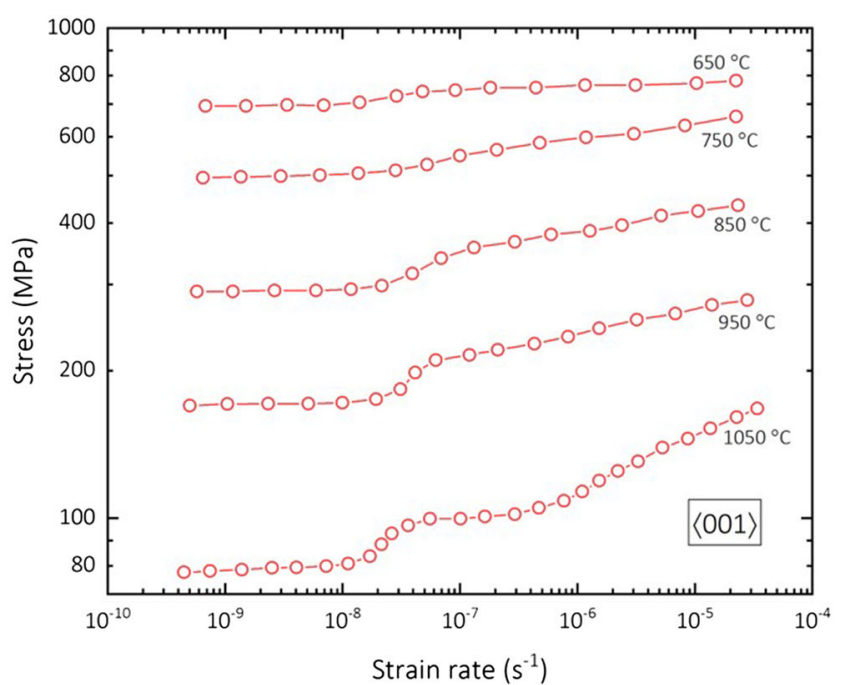

(b)

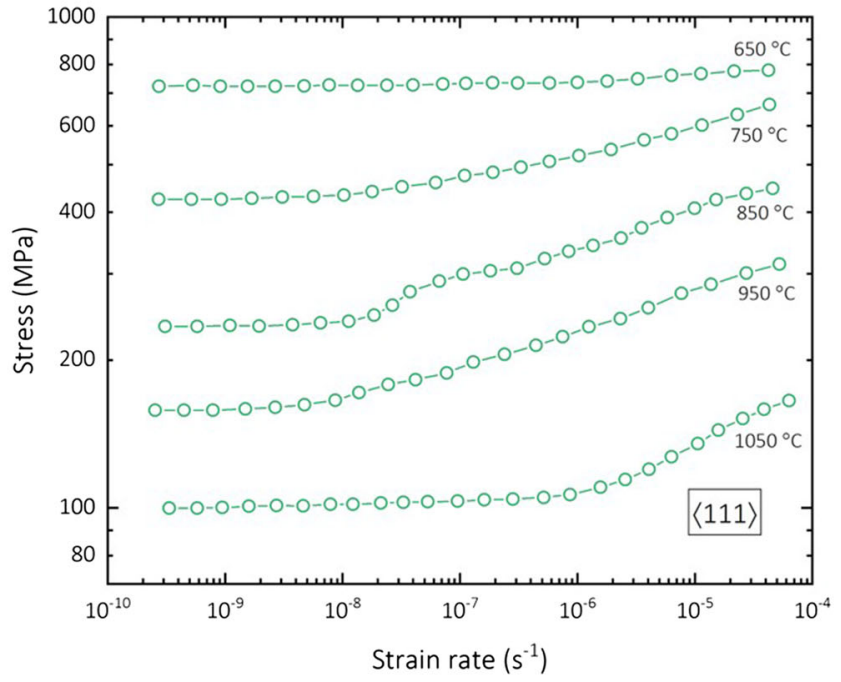

(d)

Fig. 11-Double-logarithmic plots of strain rate over applied stress extracted from SRT between 650 and $1050{ }^{\circ} \mathrm{C}$. A comparison of all results is shown in $(a)$. SRT data are then presented separately for the $(b)\langle 001\rangle$ direction, $(c)\langle 011\rangle$ direction, and $(d)\langle 111\rangle$ direction. Arrows indicate testing temperatures in cases in which lines are overlapping.

$$
\dot{\varepsilon}_{\mathrm{s}}=A \sigma_{\mathrm{app}}^{n} \exp \left(-\frac{Q_{\mathrm{app}}}{R T}\right),
$$

where $A$ is a material-specific constant, $n$ is the stress exponent, $R$ is the gas constant, $\sigma_{\text {app }}$ is the measured apparent proof stress, and $Q_{\text {app }}$ is the apparent activation energy. Equation [3] can be rearranged to yield a plot of $\ln \left(\sigma_{\text {app }}\right)$ vs $1 / T$, in which the slope will be equal to $Q_{\text {app }} / R n$. Results of this analysis are shown for the three crystal directions in Figures 10(a) through (c). The dashed lines used to extract estimates for $Q_{\text {app }}$ were fitted to experimental data from lower strain rate tests.

Qualitative results confirm that resistance to high-temperature creep deformation increases from the $\langle 011\rangle$ to the $\langle 111\rangle$, and finally to the $\langle 001\rangle$ direction.
Quantitative values are obtained assuming a constant stress exponent of 8 for this range of strain rates and temperatures, chosen based on the SRT results presented in Figure 12. This leads to apparent activation energies of 1028,620 , and $631 \mathrm{~kJ} / \mathrm{mol}$. In normalized terms, these figures correspond to $75.9 R T_{\mathrm{m}}, 45.8 R T_{\mathrm{m}}$, and $46.5 R T_{\mathrm{m}}$, with the melting temperature $T_{\mathrm{m}}$ of 1630 $\mathrm{K}$ predicted by Thermo-Calc. Activation energies must be considered carefully, as they are directly influenced by the chosen stress exponent, which in turn corresponds to an apparent, extrapolated value rather than an effective, phenomenological one.$^{[44,45]}$ Nonetheless, these figures are in fair agreement with values of $41 R T_{\mathrm{m}}$, reported by Carey and Sargent ${ }^{[46]}$ for IN738LC, and of $53.3 R T_{\mathrm{m}}$, obtained by Sajjadi and Nategh ${ }^{[47]}$ for GTD-111 in this regime. 


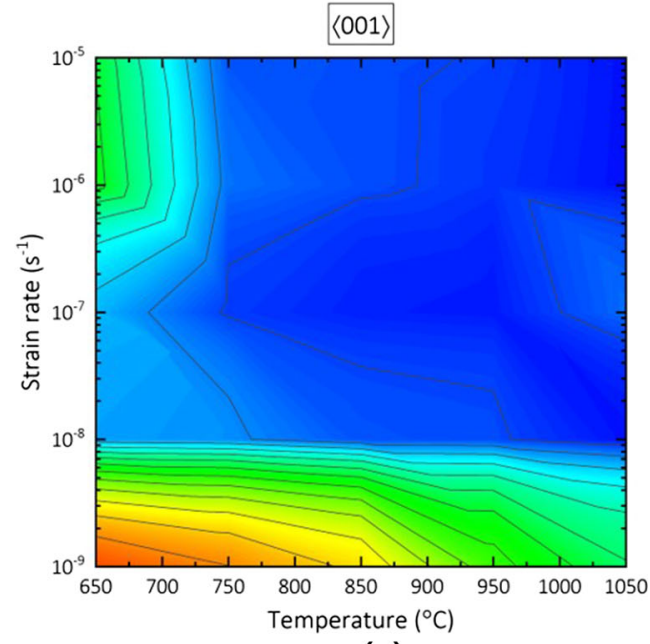

(a)
Exponent $\mathrm{n}$

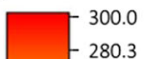

$-280.3$ 260.6 240.8 221.1 201.4 181.6 161.9 142.2 22.4 102.7 (102.7 63.21 43.47

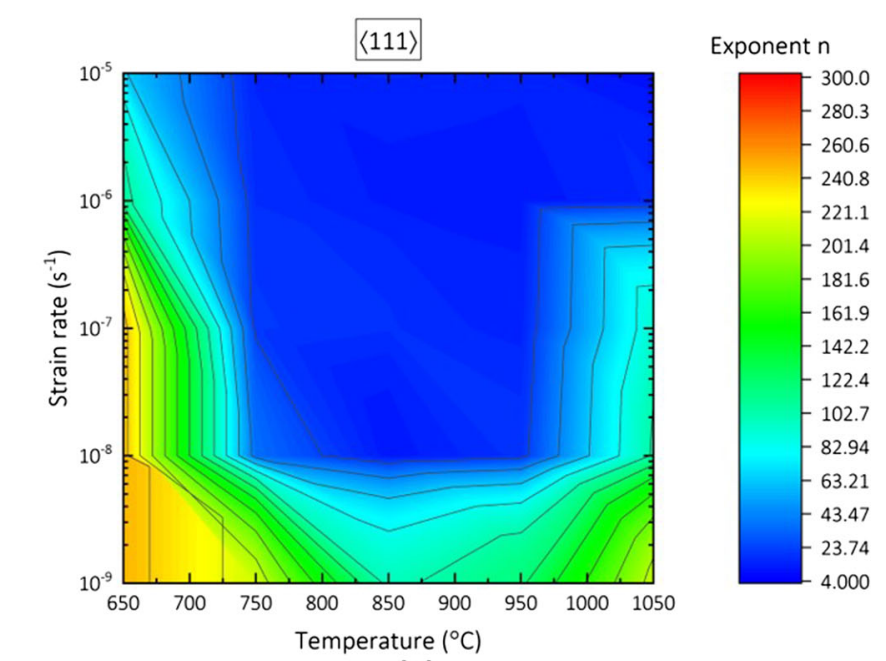

(c)

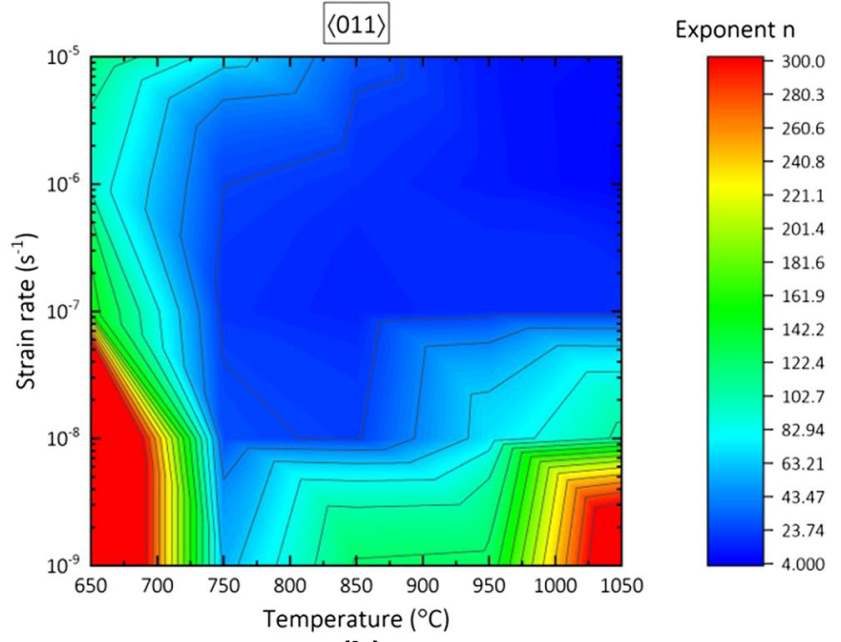

(b)

Fig. 12- Contour maps of the apparent stress exponent as a function of temperature and strain rate for the $(a)\langle 001\rangle$ direction, $(b)\langle 011\rangle$ direction, and $(c)\langle 111\rangle$ direction. Quantitative values are shown next to the color bars. Minimum and maximum values were manually set to 4 and 300, and 16 linearly distributed major levels were generated in between. Dark gray lines mark the limits of individual major levels.

\section{Stress Relaxation Tests}

Stress relaxation testing has been used to rapidly assess creep performance, building on efforts made elsewhere. ${ }^{[48-51]}$ This method aims to quantify remaining creep resistance - before or after service exposure - and represents a paradigm shift away from attempting to re-create microstructural damage evolution, as is carried out in a regular creep test. ${ }^{[24]}$ Several recent studies have made use of SRT for the mechanical characterization of superalloys and have shown results consistent with conventional creep data from the literature, thus enabling accelerated testing campaigns of new alloys. ${ }^{[52-54]}$ Here, in common with such approaches, it is assumed that the total strain rate of the system remains in equilibrium as crosshead displacement is fixed, consistent with:

$$
\dot{\varepsilon}_{\mathrm{t}}=\dot{\varepsilon}_{\mathrm{p}}+\dot{\varepsilon}_{\mathrm{e}}+\dot{\varepsilon}_{\mathrm{m}}=0,
$$

where $\dot{\varepsilon}_{\mathrm{t}}, \dot{\varepsilon}_{\mathrm{p}}$, and $\dot{\varepsilon}_{\mathrm{e}}$ are the total, the plastic, and the elastic strain rates of the specimen, and $\dot{\varepsilon}_{\mathrm{m}}$ is the elastic strain rate of the testing apparatus. Plastic strain rate can then be expressed following Reference 55 as:

$$
\dot{\varepsilon}_{\mathrm{p}}=-\frac{\dot{\sigma}}{E}-\frac{A \dot{\sigma}}{L k_{\mathrm{m}}}=-\frac{\dot{\sigma}}{E_{\mathrm{app}}},
$$

where $\dot{\sigma}$ is the change in stress with time during load relaxation and $E_{\text {app }}$ is the apparent modulus of the material. The latter can be calculated using $E$ as the elastic modulus, $A$ as the sample cross section, $k_{\mathrm{m}}$ as the stiffness of the machine, and $L$ as the specimen gauge length. While $k_{\mathrm{m}}$ is unknown, it can be estimated by analyzing elastic data obtained during loading and/or unloading. ${ }^{[24,55]}$

As load relaxation occurs across the ETMT specimen, and not only in the central high-temperature region, slight changes in total strain cannot be avoided. Here, 


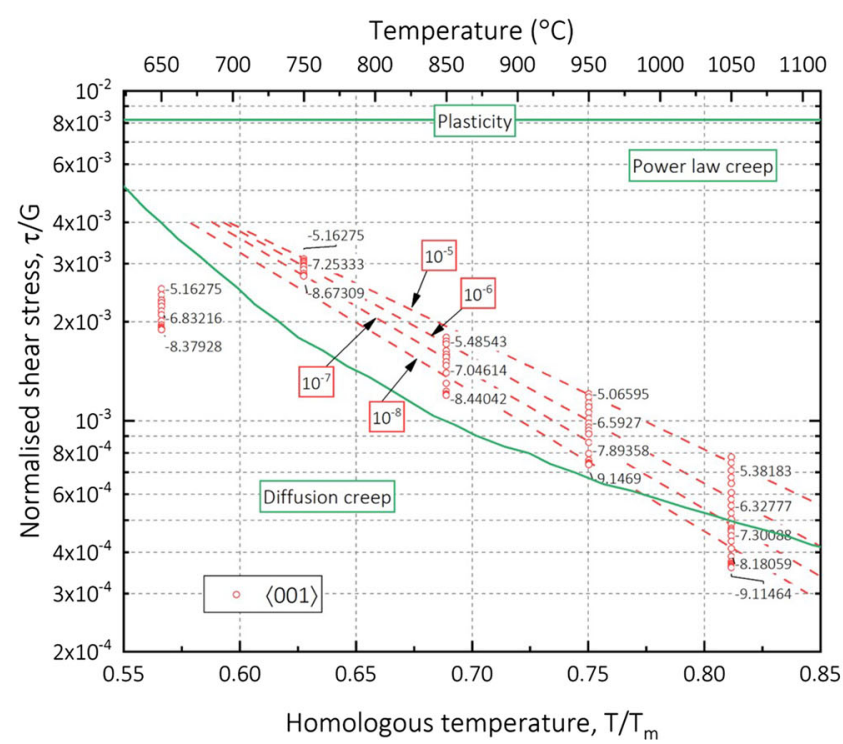

(a)

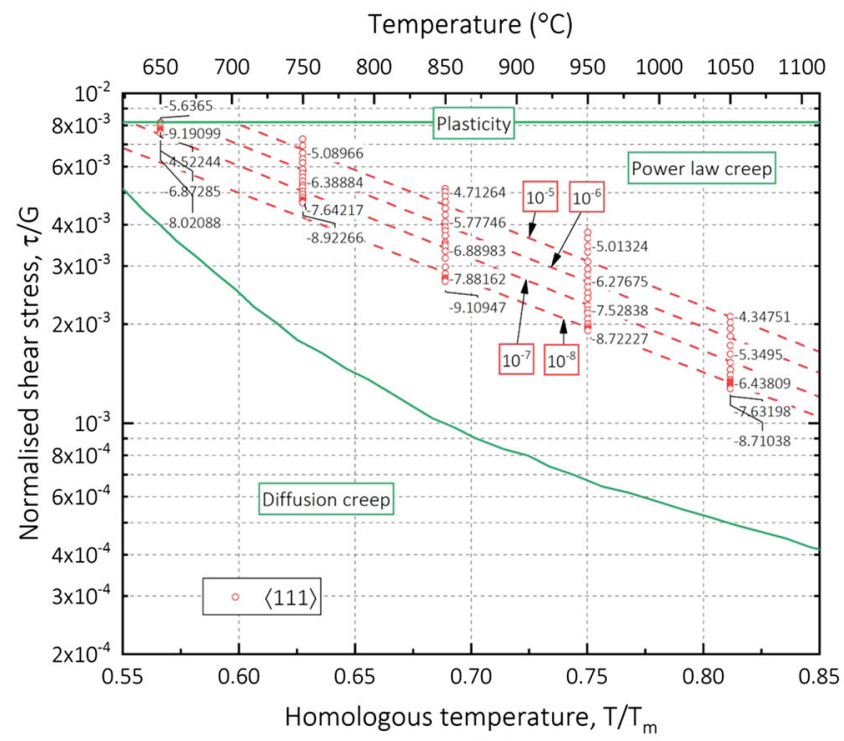

(c)

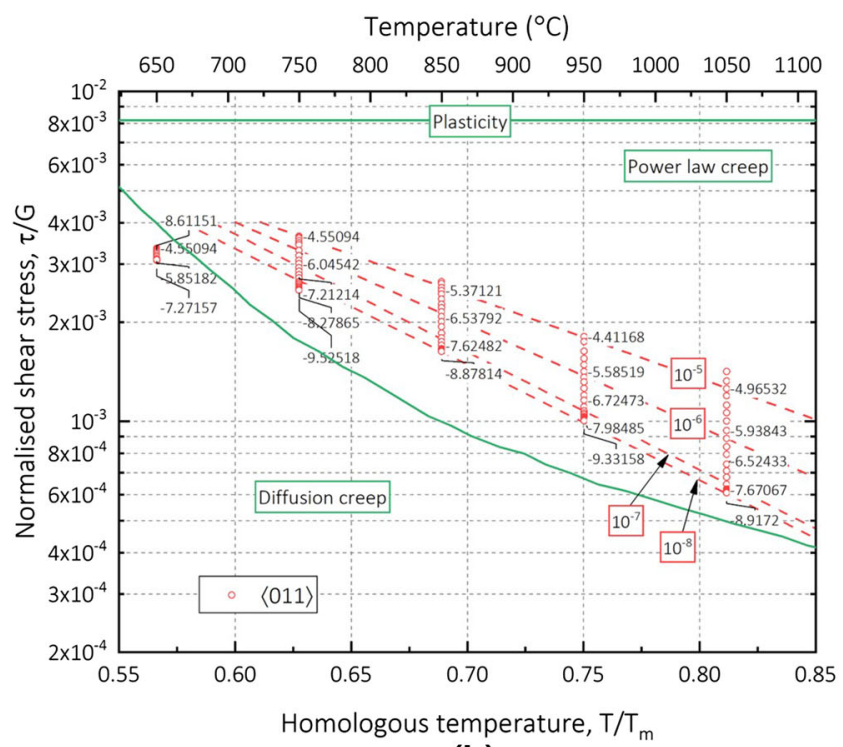

(b)

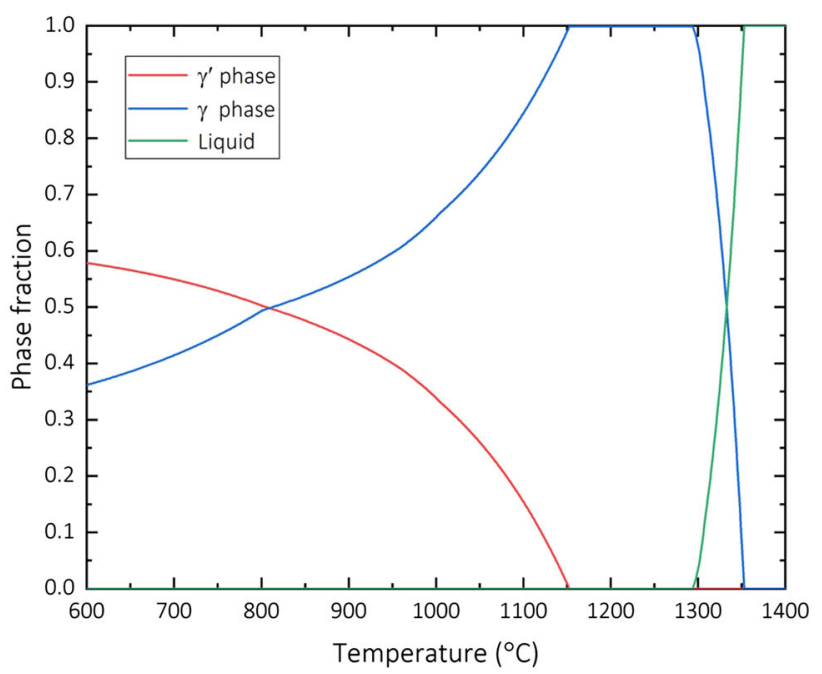

(d)

Fig. 13 - Stress/temperature deformation mechanism maps for material deformed along the $(a)\langle 001\rangle$ direction, $(b)\langle 011\rangle$ direction, and $(c)\langle 111\rangle$ direction. Contours of shear strain rate are given in $\mathrm{s}^{-1}$. Field boundaries reported by Frost and Ashby ${ }^{[58]}$ for conventionally cast Mar-M200 material are added for comparison. The plot in $(d)$ shows changes in $\gamma, \gamma^{\prime}$, and liquid phase fractions for the SIT superalloy predicted by Thermo-Calc using the Ni-alloy database TTNi8.

these have been measured with DIC in the central $3 \mathrm{~mm}$ of the specimen to provide a correction for Eq. [5], yielding $\dot{\varepsilon}_{\mathrm{p}}=\dot{\varepsilon}_{\mathrm{t}}-\dot{\sigma} / E_{\mathrm{app}}$. Application of this correction has been found to be especially important for the first minutes of relaxation, during which the ETMT apparatus contracts elastically as the applied load decreases. Longer-term SRT results are not affected by the finite stiffness of the load frame and corrections to Eq. [5] are minimal. $^{[55]}$

Curves of applied stress over plastic strain rate are presented on double logarithmic plots in Figure 11(a) through (d). Noticeable changes in gradient occur at intermediate strain rates, giving the curves a characteristically sigmoidal shape.
By using the approach depicted in Figure 4(a), the apparent stress exponent, $n$, can be obtained as a function of the logarithmic values of stress, $\sigma$, and strain rate, $\dot{\varepsilon}_{\mathrm{p}}$, consistent with:

$$
n=\left.\frac{\partial \log \dot{\varepsilon}_{\mathrm{p}}}{\partial \log \sigma}\right|_{\varepsilon, T}
$$

for given values of total strain and temperature. Application of this equation locally to segments of the stress-strain rate curves allows contour maps to be derived for the apparent stress exponent at strain rates between $10^{-5}$ and $10^{-9} / \mathrm{s}$ and temperatures between 650 ${ }^{\circ} \mathrm{C}$ and $1050{ }^{\circ} \mathrm{C}$, as shown in Figure 12(a) through (c). 
These can be regarded as Ashby-type high-temperature deformation mechanism maps and can be derived rather rapidly with the ETMT approach.

An initial decrease in the apparent stress exponent has been observed for tests performed above $750{ }^{\circ} \mathrm{C}$ at strain rates between $10^{-6}$ and $10^{-8} / \mathrm{s}$. This occurs earlier in the test, i.e. at higher strain rates, as the temperature increases. Similar behavior has been reported by Nathal et $a .^{[53]}$ for the first-, second-, and fourth-generation single-crystal superalloys, NASAIR 100, CMSX-4, and EPM-102. These authors showed that the effect disappears if the specimens are crept prior to stress relaxation, as the pre-rafted microstructure offers higher resistance to primary creep. As such, this transition can be related to a shift from primary creep deformation, dominated by APB shearing of $\gamma^{\prime}$ precipitates, to tertiary creep, dominated by dislocation climb bypass. Transition stress values at different temperatures are in accordance with the deformation mechanism maps for nickel-based superalloys proposed by Smith et al. ${ }^{[56]}$ and Barba et $a l .^{[22]}$ No transition is clear at $650{ }^{\circ} \mathrm{C}$, probably because this temperature is too low to enable diffusional climb around the precipitates.

Values of apparent stress exponents associated with primary and tertiary creep, respectively, decrease with increasing temperature. This reduction has been shown to be related to directional coarsening of precipitates at higher temperatures. ${ }^{[53]}$ It should be noted that these figures cannot be readily related to effective stress exponents used in creep models, as explained by Carry and Strudel for both primary ${ }^{[4]}$ and tertiary creep. ${ }^{[45]}$ Discrepancies between apparent and effective exponents were also confirmed by the experimental results of Dupeux et al. from stress relaxation ${ }^{[55]}$ and conventional creep tests $^{[57]}$ on CMSX-2. At strain rates below $10^{-} 8 / \mathrm{s}$, apparent stress exponents show a significant rise, with values that can no longer be rationalized by any type of high-temperature deformation mechanisms. As opposed to a standard creep test, the driving force for directional coarsening and creep strain accumulation decreases with time during SRT and exceedingly tends towards zero. Nathal et al. ${ }^{[53]}$ observed no further microstructural changes when comparing specimens relaxed at $982{ }^{\circ} \mathrm{C}$ for 100 and 370 hours. As such, once a steady-state stress value has been reached, the results from SRT are increasingly affected by mechanical noise and provide little further insight into high-temperature damage accumulation mechanisms.

SRT data can also be presented in the form of stress/ temperature deformation mechanism maps, following Frost and Ashby. ${ }^{[58]}$ The resulting maps shown in Figure 13(a) through (c) provide a means of visualizing material performance in different deformation regimes and of comparing normalized results to data from the literature. ${ }^{[46,47]}$

As discussed by Frost and Ashby, ${ }^{[58]}$ any deformation mechanism can be described by a rate equation of the form:

$$
\dot{\gamma}=f\left(\tau, T, S_{i}, P_{j}\right)
$$

This relates shear strain rate, $\dot{\gamma}$, to shear stress, $\tau$, temperature, $T$, a set of $i$ state variables, $S_{i}$, describing the current microstructural state of the material, and a set of $j$ material properties, $P_{j}$, which are inherent to the material. Key simplifying assumptions are that steady-state conditions are reached during deformation and that material properties and state variables either remain constant or are directly determined by $\tau$ and/or $T$. This leads to a reduction of Eq. [7] to $\dot{\gamma}=f(\tau, T)$.
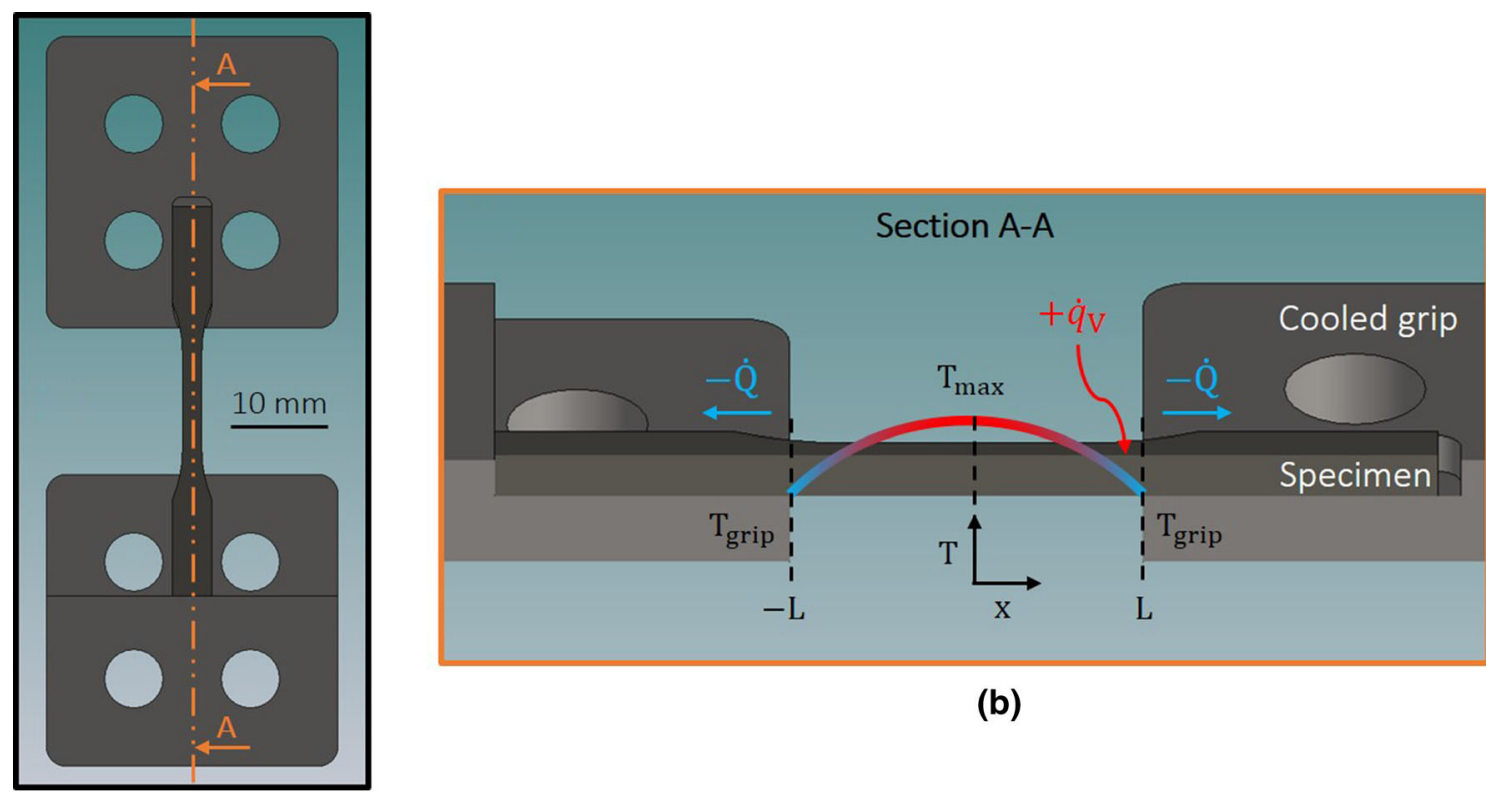

(b)

(a)

Fig. 14-(a) CAD-derived drawing of a gripped ETMT specimen. (b) Schematic representation of heat conduction in an ETMT specimen with heat generation from Joule heating. 
In order to construct maps following Frost and Ashby, the tensile stress/strain data from Figure 11 are first converted to shear stress/strain. Geometrical transformation factors were chosen following the work of Ghosh et al., ${ }^{[59]}$ who modeled the crystallographic anisotropy of tensile creep deformation in single-crystal superalloys. These authors assumed that macroscopic creep deformation results from glide on both the $\{111\}\langle\overline{1} 01\rangle$ and $\{001\}\langle 110\rangle$ systems, while neglecting macroscopic contributions from $\{111\}\langle\overline{1} \overline{1} 2\rangle$ slip vectors. Their work contains an in-depth discussion on the predicted number of active slip systems and their respective Schmid factors, leading to geometrical conversions for each orientation. ${ }^{[59]}$

In a second step, shear stress and temperature values are normalized with respect to shear modulus and melting temperature. The aforementioned value of 1630 $\mathrm{K}$ predicted by Thermo-Calc and TTNi8 for $T_{\mathrm{m}}$ is used to calculate the homologous temperature (see Figure 13(d)). Values for temperature-dependent shear

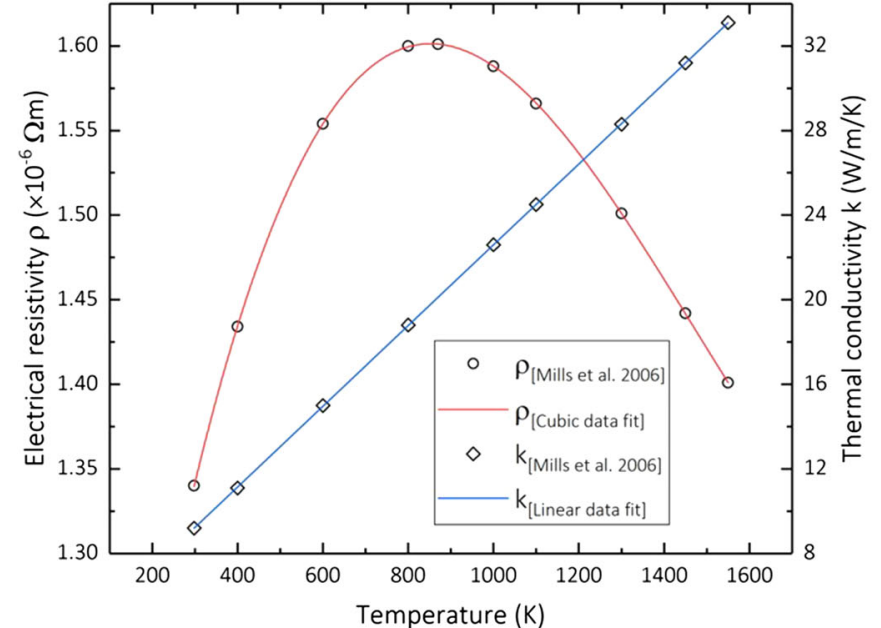

(a)

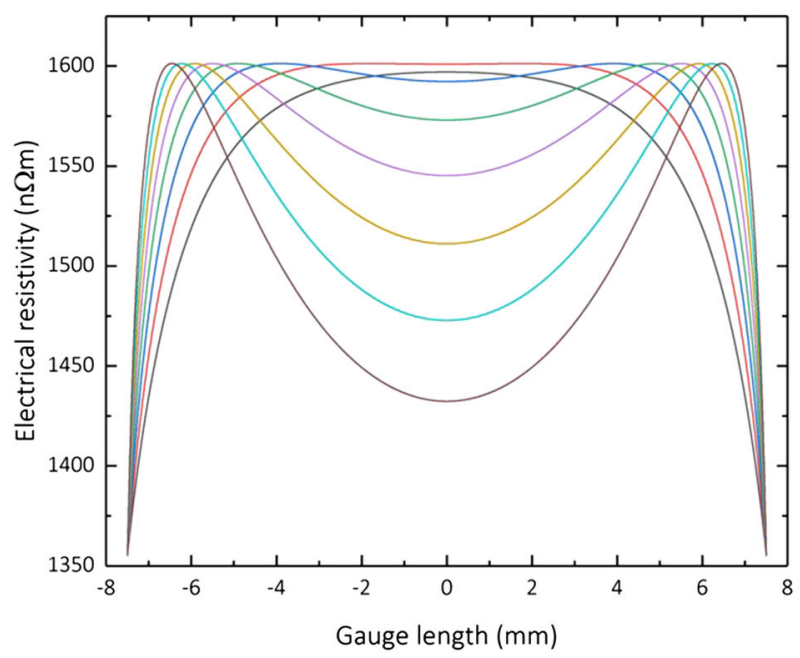

(c) moduli, $G(T)$, were obtained for each individual orientation from high-temperature dynamic resonance measurements at NPL. These are the same assessments mentioned in Section II-E with regards to obtaining temperature-dependent elastic moduli, $E(T)$, for each orientation.

As suggested by Frost and Ashby, data points in Figure 13 are labeled with the value of the third macroscopic variable, in this case $\log (\dot{\gamma})$. The red dashed lines represent contours of constant shear strain rate based on data between $750{ }^{\circ} \mathrm{C}$ and $1050{ }^{\circ} \mathrm{C}$. The solid green lines divide fields dominated by power law creep, diffusion creep, and low-temperature plasticity controlled by dislocation glide. These boundaries were reported for Mar-M200 material with a large grain size of around $1 \mathrm{~cm}$, which can be taken as an estimate of directionally solidified or single-crystal material behavior $^{[58]}$ and offer a benchmark for the SIT superalloy. A further power law breakdown regime dominated by APB shearing of $\gamma^{\prime}$ precipitates can be inferred in the

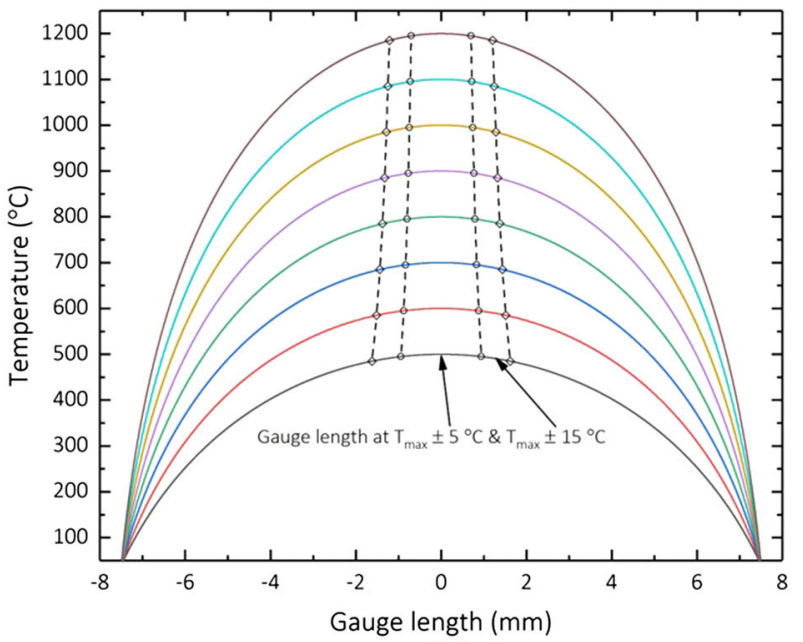

(b)

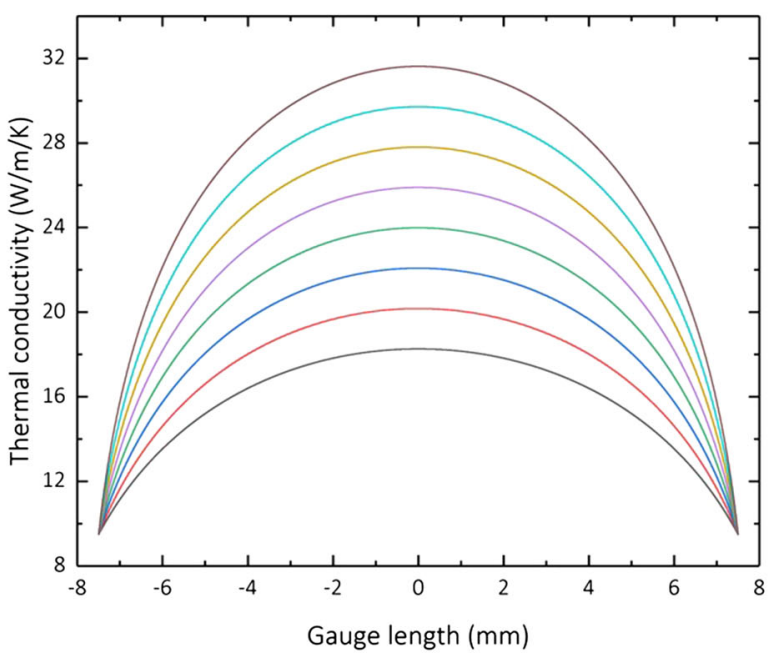

(d)

Fig. 15- (a) Cubic and linear fits for electrical resistivity and thermal conductivity data obtained by Mills et al. ${ }^{[61]}$ for CMSX-4. Modeling results for the distribution of $(b)$ temperature, $(c)$ electrical resistivity, and $(d)$ thermal conductivity along a heated ETMT specimen. The dotted lines in the temperature distribution graph mark regions predicted to remain, respectively, at $T_{\max } \pm 5{ }^{\circ} \mathrm{C}$ and $T_{\max } \pm 15^{\circ} \mathrm{C}$. 
upper left corner of the maps and would include data at $650{ }^{\circ} \mathrm{C}$. The lower limit of this area is estimated at around $10^{-2} G^{[58]}$

\section{DISCUSSION}

\section{A. Validity and Limitations of the ETMT System}

In this work, it has been demonstrated that the ETMT offers substantial practical advantages associated with testpiece miniaturization. Nevertheless, a critical issue concerns whether or not results are comparable to those obtained from established techniques which are regarded as more standardized. In particular, one should be concerned with (1) real size effects - such as the effect of oxidation damage at low strain rates - and (2) potential errors and increased data scatter arising from sub-scale testing.

In this context, several generic issues have been identified. ${ }^{[11,12]}$ First, a minimum representative material volume must be sampled. This may be less of an issue for the case of single-crystal specimens; however, it poses a significant challenge for testing polycrystalline materials with grain sizes of the order of testpiece width/ thickness. Second, there is an increased probability that small defects or heterogeneities will affect bulk material response. Considering the good quality of the castings - which exhibit low levels of porosity and reduced segregation after heat treatment - this point may not be so vital to consider. Third, test specimens must be carefully manufactured and mechanically finished to reduce the possibility of surface residual stresses or re-cast layers influencing the results. Preparation steps taken to avoid this are described in Section II-A. Last, uncertainties associated with measurements of load (stress), temperature, and strain must be critically assessed. The effect of temperature heterogeneity along

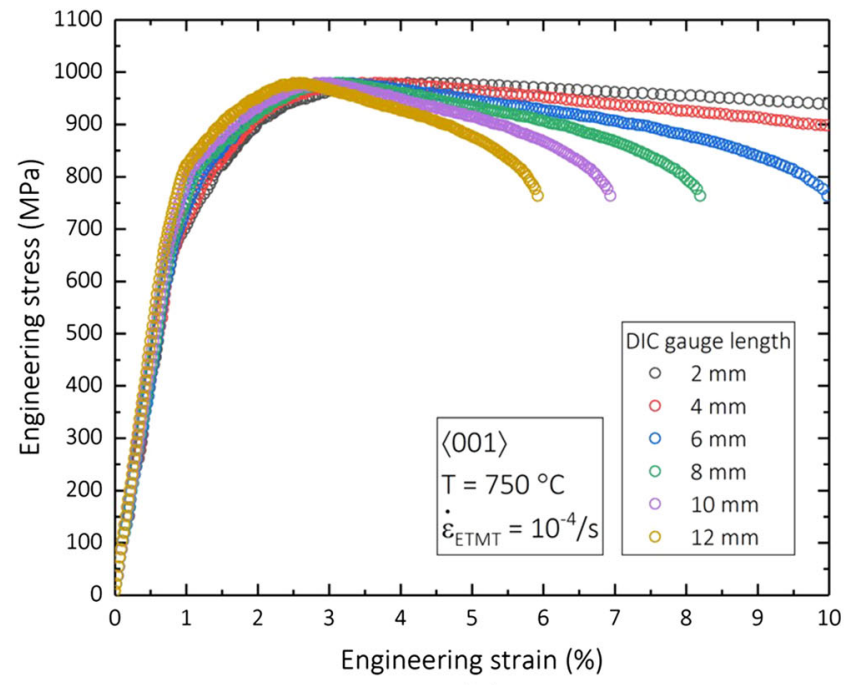

(a) the sample and the accuracy of DIC strain measurements are discussed in the following. Here, accumulated errors in load are not considered, as the $5-\mathrm{kN}$ load cell was calibrated against a reference before the testing campaign.

\section{Modeling of the temperature distribution in ETMT} specimens

Previous ETMT studies ${ }^{[4,19,23]}$ have reported a uniform temperature distribution in the central 2 to $4 \mathrm{~mm}$ of the specimen. However, these observations are based on limited experimental results and lack validation by modeling. This issue is considered in greater detail here.

For a given material volume containing a heat source, the temperature distribution $T(x, y, z, t)$-depending on three spatial variables $(x, y, z)$ and the time variable $t$ - can be expressed by the heat equation:

$$
c_{\mathrm{p}} \rho \frac{\partial T}{\partial t}-k\left(\frac{\partial^{2} T}{\partial x^{2}}+\frac{\partial^{2} T}{\partial y^{2}}+\frac{\partial^{2} T}{\partial z^{2}}\right)=\dot{q}_{\mathrm{V}} .
$$

Here, $c_{\mathrm{p}}$ is the specific heat capacity, $\rho$ is the mass density of the material, $k$ is the thermal conductivity, and $\dot{q}_{\mathrm{V}}$ represents the volumetric heat source. Three assumptions are made at this point to simplify the integration of Eq. [8].

First, a steady-state case is considered, in which the heat equation is not dependent on time, so that $\partial T / \partial t=0$. For temperature or current control, the Instron (C) ETMT system uses a high bandwidth 8800 servo-hydraulic controller with a maximum internal acquisition and control loop sampling rate of $10 \mathrm{kHz}$. This high bandwidth enables fast and accurate control even when large heating or cooling rates are required. ${ }^{[23]}$ With well-tuned PID control parameters, the system shows an immediate response to changes in the command channel, as well as very good long-term stability. As such, steady-state conditions are a reasonable

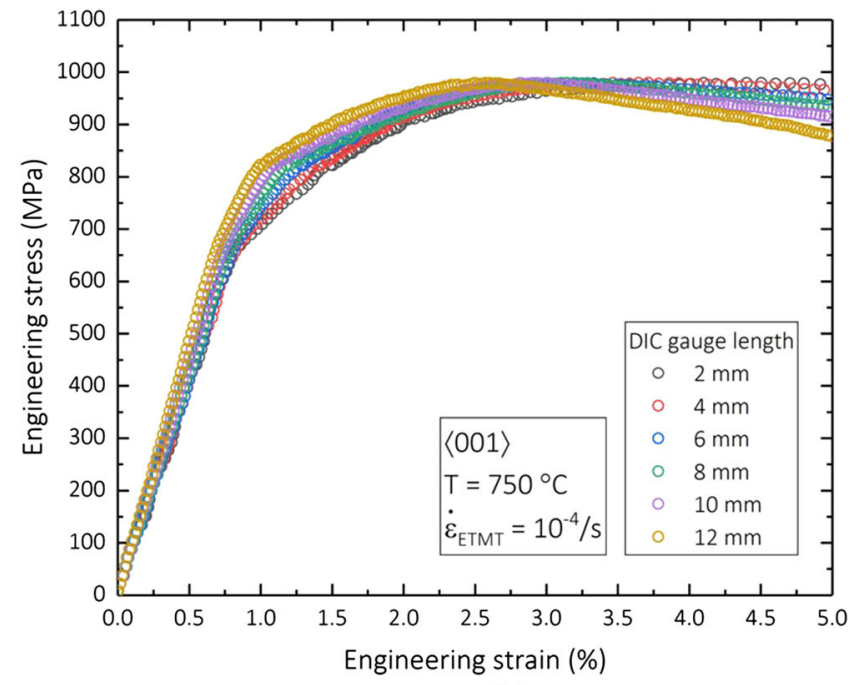

(b)

Fig. 16-Effects of selected virtual gauge length for DIC strain measurements on experimental results. A test on the $\langle 001\rangle$ direction at $750{ }^{\circ} \mathrm{C}$ and $10^{-4} / \mathrm{s}$ was chosen for this analysis. Results are plotted up to $(a) 10$ pct engineering strain to provide an overview of the test, and $(b) 5$ pct engineering strain to provide a more detailed view of the elastic regime and initial yielding. 


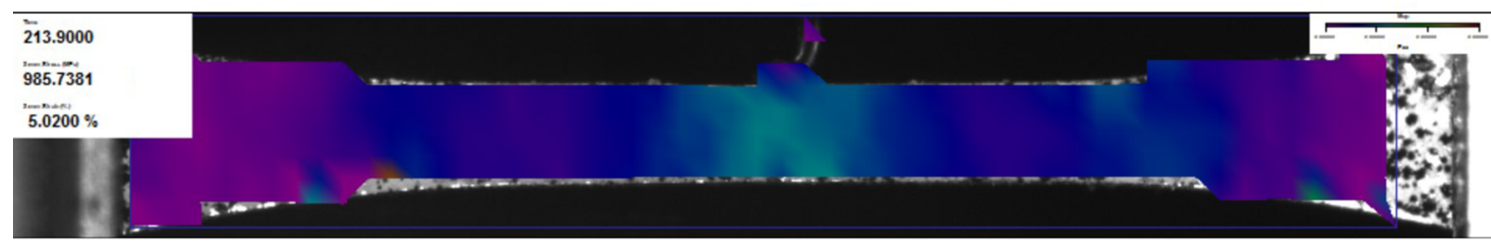

(a)

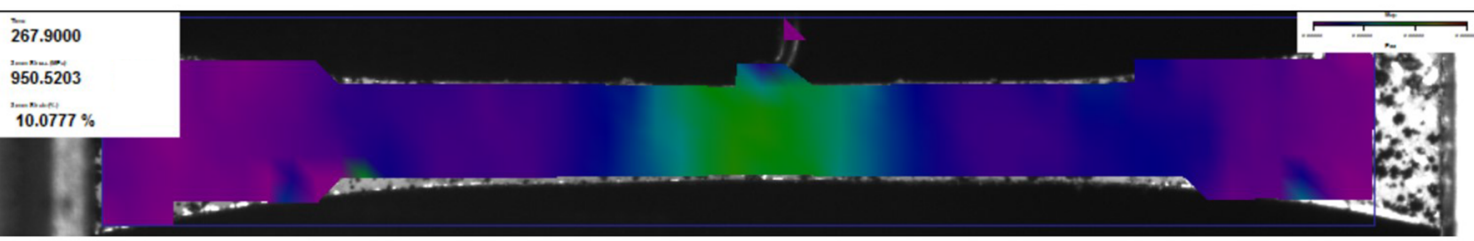

(b)

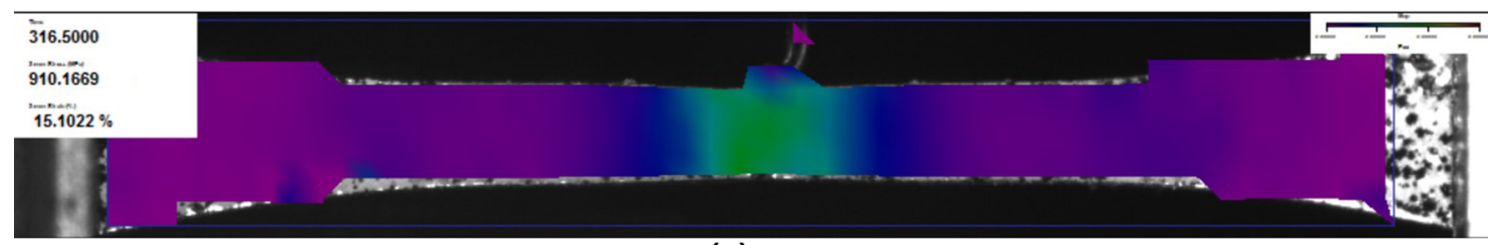

(c)

Fig. 17-2D color maps of strain distribution in a $\langle 001\rangle$ specimen tested at $750{ }^{\circ} \mathrm{C}$ and $10^{-3} / \mathrm{s}$. Results are shown for total strain levels of $(a)$ 5 pct, (b) 10 pct, and (c) 15 pct.

assumption, even in the case of stepped-temperature tests.

Second, the heat equation is treated as a one-dimensional problem, in which the temperature only varies along the tensile axis of the specimen, chosen here as the $x$ spatial coordinate, as shown in Figure 14. While the temperature will also vary across the width and thickness of the testpiece, relative differences are much smaller than along the tensile axis. Equation [8] can now be simplified to:

$$
-k\left(\frac{\partial^{2} T}{\partial x^{2}}\right)=\dot{q}_{\mathrm{V}}
$$

Third, an additional negative term of the form $-\mu T$ can be added to Eq. [9] to account for radiative heat loss to the immediate environment. However, it is assumed here that cooling rates are primarily determined by the thermal diffusivity of the specimen and by heat loss to the water-cooled grips, and that radiation can be neglected. While this final assumption is incorrect at very high temperatures, it should not have a significant impact on modeling results for temperatures below $1100{ }^{\circ} \mathrm{C} \cdot{ }^{[23]}$

The volumetric heat source $\dot{q}_{\mathrm{V}}$ for a certain portion of the testpiece volume can be described using Joule's first law and Ohm's law as:

$$
\dot{q}_{\mathrm{V}}=\frac{P_{\mathrm{V}}}{\Delta V}=\frac{I^{2} R}{\Delta x A}=\frac{I^{2} \rho}{A^{2}},
$$

where $P_{\mathrm{V}}$ is the power converted from electrical to thermal energy in a volume element $\Delta V, I$ is the current traveling through the testpiece, $R$ is the electrical resistance, $\rho$ is the electrical resistivity, and $A$ is the specimen cross section.

The boundary conditions necessary to solve Eq. [9] uniquely are that temperature at the gripped ends, $T( \pm L)=T_{\text {grip }}$, remains constant during testing. This yields the one-dimensional temperature distribution:

$$
\begin{aligned}
T(x) & =\dot{q}_{\mathrm{V}} \frac{L^{2}}{2 k}\left(1-\frac{x^{2}}{L^{2}}\right)+T_{\text {grip }} \\
& =\left(\frac{I}{A}\right)^{2} \frac{L^{2}}{2}\left(1-\frac{x^{2}}{L^{2}}\right) \frac{\rho}{k}+T_{\text {grip }} .
\end{aligned}
$$

It can be seen that temperature scales with the square of applied current over the specimen cross section. The term $T_{\text {grip }}$ has been measured during testing at high temperatures and remains constant at around $40{ }^{\circ} \mathrm{C}$. For the case of the larger ETMT testpiece geometry chosen for stress relaxation tests, $A$ is equal to $4 \mathrm{~mm}^{2}$ and $L$ to $7.5 \mathrm{~mm}$.

The two remaining material parameters - electrical resistivity, $\rho$, and thermal conductivity, $k$ - both depend on chemical composition and on temperature, thus requiring a discrete solution of Eq. [11]. Considering that the same master heat was used to cast all the bars, it is anticipated that temperature distribution will not depend on orientation. Several extensive studies have discussed the measurement and calculation of 


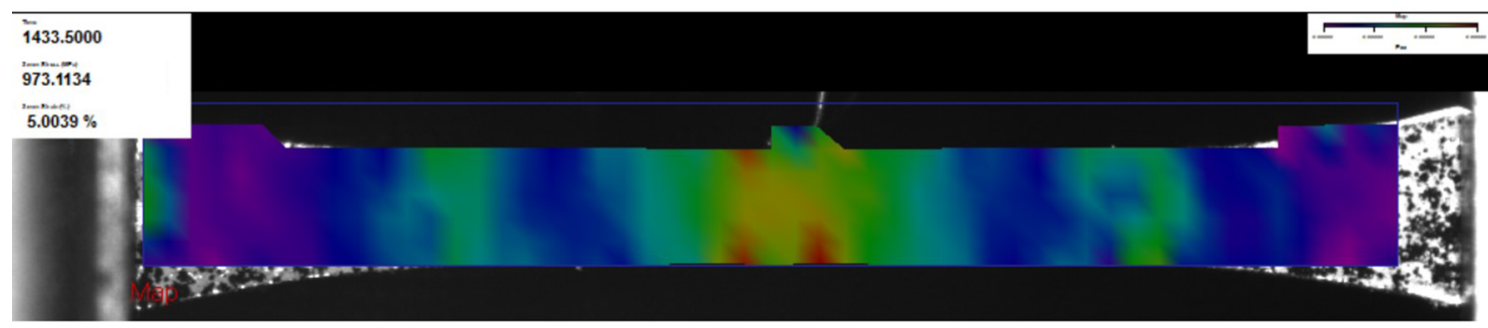

(a)

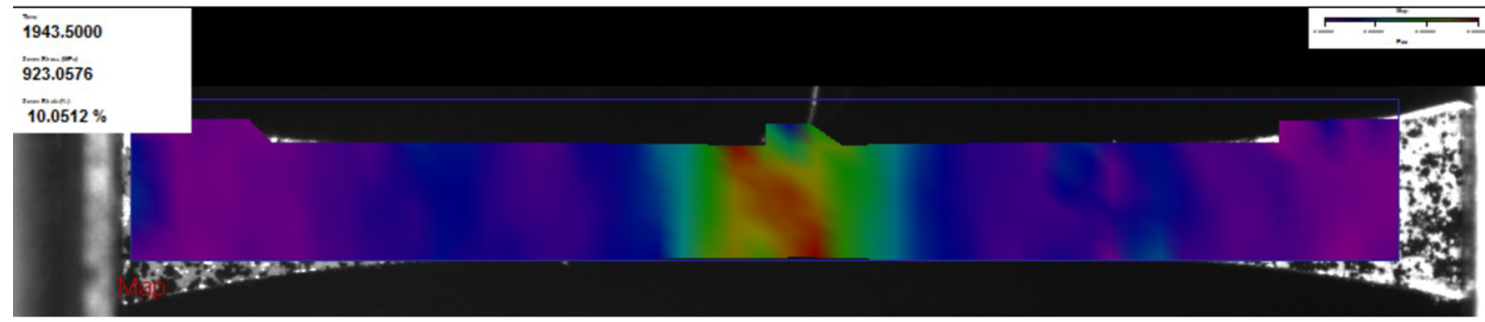

(b)

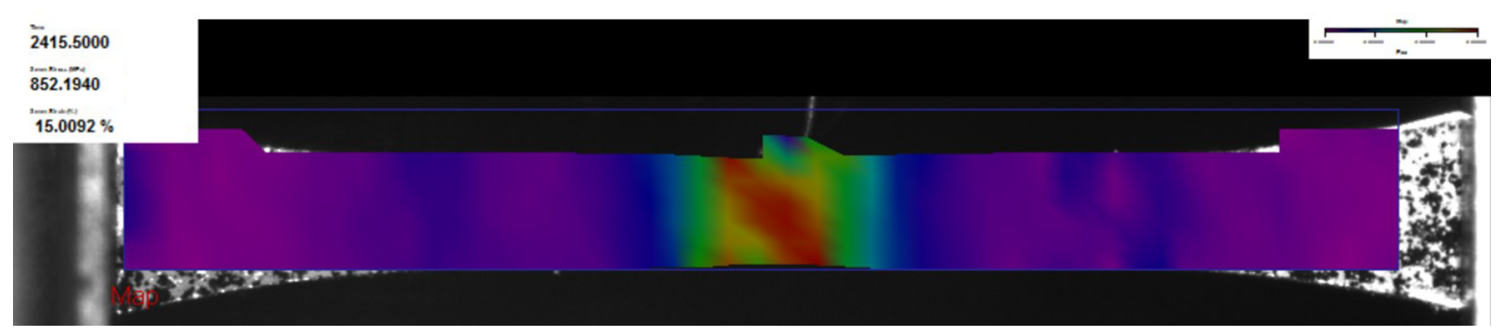

(c)

Fig. 18-2D color maps of strain distribution in a $\langle 001\rangle$ specimen tested at $750{ }^{\circ} \mathrm{C}$ and $10^{-4} / \mathrm{s}$. Results are shown for total strain levels of $(a)$ 5 pct, (b) 10 pct, and (c) 15 pct.

thermophysical properties of superalloys. ${ }^{[60-62]}$ In the present work, results obtained for the second-generation single-crystal superalloy CMSX-4 at temperatures between 298 and $1550 \mathrm{~K}$ are used as estimates for the SIT superalloy. ${ }^{[61]}$ Data for $\rho(T)$ and $k(T)$ are fitted using a cubic and a linear equation, respectively, as shown in Figure 15(a):

$$
\begin{aligned}
\rho(T)= & 9.06032 \times 10^{-7}+1.88864 \\
& \times 10^{-9} T-1.55977 \times 10^{-12} T^{2}+3.53139 \\
& \times 10^{-16} T^{3} \quad[\Omega \mathrm{m}] \\
k(T)= & 3.50617+0.01909 T \quad\left[\mathrm{~W} \mathrm{mK}^{-1}\right]
\end{aligned}
$$

The applied current, $I_{\text {app }}$, is registered during testing. However, due to previous imprecise assumptions and estimates, the temperature calculated for the center of the specimen using $I_{\text {app }}$ in Eq. [11] does not exactly match $T_{\max }$. As such, a current correction parameter, $I_{\text {corr }}$, is introduced to ensure that $T(0)=T_{\max }$.

Modeling results for the distribution of temperature, electrical resistivity, and thermal conductivity in ETMT specimens between $500{ }^{\circ} \mathrm{C}$ and $1200{ }^{\circ} \mathrm{C}$ are shown in Figure 15(b) through (d). Qualitative and quantitative results are in good agreement with previous findings. ${ }^{[4,19]}$ The section of the testpiece at $T_{\max } \pm 5{ }^{\circ} \mathrm{C}$ decreases with increasing temperature. It is predicted to be $1.67 \mathrm{~mm}$ at $700{ }^{\circ} \mathrm{C}$ and $1.54 \mathrm{~mm}$ at $900{ }^{\circ} \mathrm{C}$, close to the experimentally determined values of $2.4 \mathrm{~mm}$ and $2.2 \mathrm{~mm}$, respectively, for the disc superalloy RR1000. ${ }^{[19]}$ Modeling predicts that the central $3-\mathrm{mm}$ region observed for DIC strain measurements remains at a reasonably uniform temperature of $\pm 15^{\circ} \mathrm{C}$. These results are an important validation of temperature distribution in ETMT specimens, and they furthermore highlight the importance of precise, localized strain measurements in the hot zone.

\section{Non-contact strain measurements via DIC}

A recent review on miniaturized testing critically assessed a number of strain measurement techniques including LVDT, line scan cameras, capacitance gauges, electrical resistance measurements, interferometry techniques, and DIC ${ }^{[12]}$ It was concluded that, despite the modest strain resolution obtained for usual camera/lens/ FOV combinations, DIC provides substantial advantages as a full field non-contact method, especially considering ongoing developments in higher-resolution cameras and increased computing power. 
A convenient feature is that, once a test video has been recorded and stored, it can be readily post-processed using different window sizes, gauge lengths, and processing accuracy/speed parameters. An analysis of this type, exploring the effects of different gauge lengths between virtual target windows, is shown in Figure 16. An ETMT tensile test on the $\langle 001\rangle$ direction at $750{ }^{\circ} \mathrm{C}$ and an initial strain rate of $10^{-4} / \mathrm{s}$ was chosen as an example. The importance of selecting a correct reduced gauge length is evident. As this value increases, it encompasses more of the cooler regions of the specimen, in which less plastic deformation takes place. This leads to large discrepancies between analysis results at higher plastic strain values. While the impact on 0.2 pct proof stress - and on initial conditions for stepped-temperature testing - is limited, choosing an incorrect gauge length will have a strong impact on stress relaxation results through Eq. [5]. The analysis below confirms the validity of DIC strain measurements in the central $3 \mathrm{~mm}$ of the specimen.

Another useful feature of DIC - and in particular of the Video Gauge software package - is the ability to output 2D strain maps. These provide a simple way of locating strain concentrations and a direct proof that anomalous yielding is not affecting test results. In order to generate a strain map, the ROI is first divided into a grid of targets. Displacements between these targets are then continuously analyzed and used to calculate the Lagrangian strain tensor at each node of the grid. For the present calculations, the side length of the quadratic targets and their grid spacing were chosen to be 15 pixels as a compromise between spacial resolution and computing time. A filter size of 30 pixels was used to smoothen displacements around each node and to reduce image noise. Finally, changes in 2D strain distribution over time are exported as a avi video file.

Figures 17 and 18 show the development of strain distribution within ETMT specimens with $\langle 001\rangle$ orientation tested at $750{ }^{\circ} \mathrm{C}$ and initial strain rates of $10^{-3}$ and $10^{-4} / \mathrm{s}$, respectively. Individual video frames were selected for comparison at total strain levels of 5,10 , and 15 pct. The variable $E_{\mathrm{xx}}$ plotted in the color maps is the calculated strain in the tensile direction. The color range is scaled between the minimum and maximum strain values detected up to that point during the test. Some artefacts appear due to discontinuities in the ROI, commonly specimen edges or areas where the high-temperature paint layer was damaged. The 2D strain maps confirm that deformation is localized in the center of the specimen. Furthermore, they show that anomalous yielding does not impact test results. Particularly in the test at $10^{-4} / \mathrm{s}$, it is also clear that macroscopic deformation is concentrated along $\{111\}$ slip planes at a 45 deg angle to tensile loading.

\section{B. On the Potential of the ETMT for Rapid Alloy Development}

The importance of accelerated material development cycles has led to large-scale enterprises like the Materials Genome Initiative (MGI), part of the broader field of Integrated Computational Materials Engineering
(ICME). ${ }^{[2,63]}$ Several promising approaches toward alloy design have been proposed and applied to the development of new grades of superalloys. ${ }^{[64-68]}$ Furthermore, laboratory-scale process chains for rapid production of single-crystal superalloy trial castings have been successfully established. ${ }^{[69-71]}$ However, testing methods continue to be dominated by standard approaches. It can be concluded that, within the design-make-test cycle, the last segment currently offers most potential for improvement in the context of ICME goals.

The ETMT testing methods presented here offer a viable and convenient contribution to this overarching goal of more efficient and rapid materials development. Acquired data can be used to extract estimates of key material properties and to make critical decisions regarding screening and/or ranking of trial alloys during the development stage. Based on the reported dimensions of small-scale single-crystal rods, ${ }^{71]}$ and using testpiece dimensions shown in Figure 2, a sufficient number of ETMT samples for STT and SRT can be produced from each trial casting.

Stepped-temperature testing enables a rapid assessment of changes in athermal material strength with temperature at a certain deformation rate. Data obtained from STT is valuable for informing TMF and cyclic fatigue lifing models. ${ }^{[72,73]}$ In our experience, several trial alloys can be compared in only a few hours and optimal compositions can be identified. Furthermore, it should be noted that STT can be readily applied to other classes of high-temperature materials. For example, tests on titanium alloys for aerospace applications have shown that STT results capture the microstructural changes introduced by different heat treatments, and indicate a composition-dependent transition in the operating deformation mechanisms between low and high temperatures. ${ }^{[74]}$

Stress relaxation tests over a temperature range of interest can rapidly yield Ashby-type deformation mechanism maps. Plotting data in this fashion offers a direct comparison with other materials for different operating conditions. For any particular application, a target region can be added using the range of temperatures and stresses encountered in service. Contours of constant strain rate provide a first estimate for screening alloys that surpass the maximum acceptable strain rate and for ranking the remaining ones. The SRT results can be readily exported as inputs for commercial FEM software packages like ABAQUS $\odot$. This ensures that FEM simulations - increasingly applied to modeling high-temperature deformation in superalloy components ${ }^{[75-77]}$ - provide reliable quantitative results.

\section{SUMMARY AND CONCLUSIONS}

Miniaturized testing using an electro-thermal mechanical testing system has been carried out on a prototype single-crystal superalloy along the $\langle 001\rangle$, $\langle 011\rangle$, and $\langle 111\rangle$ loading axes. Compared with full-scale testing methods on testpieces of more standard geometry, the approach is advantageous owing to its 
increased speed, degree of simplicity, and the use of smaller quantities of material. The following specific conclusions can be drawn from the present study:

1. The ETMT has been shown to be a viable tool for assessing material properties of single-crystal nickel-based superalloys. Mechanical properties derived from miniaturized testing are found to be comparable to those obtained from conventional tensile tests over a range of temperatures and strain rates.

2. Stress relaxation tests and stepped-temperature tests have been used as a rapid means of extracting creep and tensile strength estimates and parameters.

3. It has been demonstrated that changes in athermal plastic deformation with temperature can be determined with a single test by ramping up the temperature during deformation at a constant strain rate. This has allowed for an estimate of the variation of flow stress with temperature.

4. Stress relaxation tests with the ETMT enable a rapid assessment of time-dependent deformation at high temperatures. Changes in operating mechanisms are revealed through deformation mechanism maps, generated using data measured at different temperatures. The results show a transition from precipitate shearing to dislocation climb bypass at higher temperatures and lower plastic strain rates.

5. Such rapid testing methodologies can be applied in studies of small-scale superalloy castings to determine both athermal and time-dependent plastic responses. This accelerated design-make-test cycle has the potential to significantly reduce the time for qualification and insertion of new grades of superalloys.

\section{ACKNOWLEDGMENTS}

Financial support and material provision from Siemens Industrial Turbomachinery AB (Finspång, Sweden) is gratefully acknowledged. The provision of the ETMT was facilitated by funding from the Engineering and Physical Sciences Research Council (EPSRC) under grant number EP/M50659X/1. RR acknowledges additional support from the EPSRC under grant number EP/M005607/01. Roger Morrell at NPL is acknowledged for his support on high-temperature measurements of elastic constants.

\section{OPEN ACCESS}

This article is distributed under the terms of the Creative Commons Attribution 4.0 International License (http://creativecommons.org/licenses/by/4.0/), which permits unrestricted use, distribution, and reproduction in any medium, provided you give appropriate credit to the original author(s) and the source, provide a link to the Creative Commons license, and indicate if changes were made.

\section{REFERENCES}

1. R.E. Schafrik and S. Walston: in Superalloys 2008: Proceedings of the Eleventh International Symposium on Superalloys, R.C. Reed, K.A. Green, P. Caron, T. Gabb, M.G. Fahrmann, E.S. Huron, and S.A. Woodward, eds., TMS, Warrendale, 2008, pp. 3-9.

2. W. Xiong and G.B. Olson: NPJ Comput. Mater., 2016, vol. 2, p. 15009.

3. T.M. Pollock: Nat. Mater., 2016, vol. 15, pp. 809-15.

4. B. Roebuck, D.C. Cox, and R.C. Reed: in Superalloys 2004: Proceedings of the Tenth International Symposium on Superalloys, K. Green, H. Harada, and T.M. Pollock, eds., TMS, Warrendale, 2004, pp. 523-28.

5. R.C. Reed, J. Moverare, A. Sato, F. Karlsson, and M. Hasselqvist: in Superalloys 2012: Proceedings of the Twelfth International Symposium on Superalloys, E.S. Huron, R.C. Reed, M.C. Hardy, M.J. Mills, R.E. Montero, P.D. Portella, and J. Telesman, eds., Wiley, New York, 2012, pp. 197-204.

6. A. Sato, Y.-L. Chiu, and R.C. Reed: Acta Mater., 2011, vol. 59, pp. $225-40$.

7. A. Sato, J.J. Moverare, M. Hasselqvist, and R.C. Reed: Metall. Mater. Trans. A, 2012, vol. 43A, pp. 2302-15.

8. J.M. Sosa, D.E. Huber, B. Welk, and H.L. Fraser: Integr. Mater. Manuf. Innov., 2014, vol. 3, p. 5 .

9. D.A. LaVan and W.N. Sharpe: Exp. Mech., 1999, vol. 39, pp. $210-16$.

10. K.J. Hemker and W.N. Sharpe: Annu. Rev. Mater. Res., 2007, vol. 37 , pp. $93-126$.

11. T.H. Hyde, W. Sun, and J.A. Williams: Int. Mater. Rev., 2007, vol. 52, pp. 213-55.

12. J.D. Lord, B. Roebuck, R. Morrell, and T. Lube: Mater. Sci. Technol., 2010, vol. 26, pp. 127-48.

13. C.C. Dyson, W. Sun, C.J. Hyde, S.J. Brett, and T.H. Hyde: Mater. Sci. Technol. 2015, pp. 1-15.

14. B. Roebuck, D. Cox, and R.C. Reed: Scr. Mater., 2001, vol. 44, pp. $917-21$

15. D.C. Cox, B. Roebuck, C.M.F. Rae, and R.C. Reed: Mater. Sci. Technol., 2003, vol. 19, pp. 440-46.

16. S. Pahlavanyali, A. Rayment, B. Roebuck, G. Drew, and C. Rae: Int. J. Fatigue, 2008, vol. 30, pp. 397-403.

17. B. Roebuck, M. Loveday, and M. Brooks: Int. J. Fatigue, 2008, vol. 30 , pp. $345-51$.

18. S. Kuhr, G. Viswanathan, J. Tiley, and H. Fraser: in Superalloys 2012: Proceedings of the Twelfth International Symposium on Superalloys, E.S. Huron, R.C. Reed, M.C. Hardy, M.J. Mills, R.E. Montero, P.D. Portella, and J. Telesman, eds., Wiley, New York, 2012, pp. 103-10.

19. A.A.N. Németh, D.J. Crudden, D.M. Collins, D.E.J. Armstrong, and R.C. Reed: in Superalloys 2016: Proceedings of the 13th International Symposium on Superalloys, M.C. Hardy, E.S. Huron, U. Glatzel, B. Griffin, B. Lewis, C. Rae, V. Seetharaman, and S. Tin, eds., Wiley, Hoboken, 2016, pp. 801-10.

20. A. Németh, D.J. Crudden, D. Armstrong, D.M. Collins, K. Li, A.J. Wilkinson, C. Grovenor, and R.C. Reed: Acta Mater., 2017, vol. 126 , pp. 361-71.

21. D. Barba, S. Pedrazzini, A. Vilalta-Clemente, A.J. Wilkinson, M.P. Moody, P. Bagot, A. Jerusalem, and R.C. Reed: Scr. Mater., 2017, vol. 127, pp. 37-40.

22. D. Barba, E. Alabort, S. Pedrazzini, D.M. Collins, A.J. Wilkinson, P. Bagot, M.P. Moody, C. Atkinson, A. Jerusalem, and R.C. Reed: Acta Mater., 2017, vol. 135, pp. 314-29.

23. B. Roebuck, M. Brooks, and A. Pearce: Good Practice Guide for Miniature ETMT Tests: Measurement Good Practice Guide No. 137: PDB: 7798; Technical Report, National Physical Laboratory Division of Materials Applications, 2016.

24. D.A. Woodford: Mater. Res. Innov., 2016, vol. 20, pp. 379-89.

25. M. Bensch, J. Preusner, R. Huttner, G. Obigodi, S. Virtanen, J. Gabel, and U. Glatzel: Acta Mater., 2010, vol. 58, pp. 1607-17.

26. M. Bensch, A. Sato, N. Warnken, E. Affeldt, R.C. Reed, and U. Glatzel: Acta Mater., 2012, vol. 60, pp. 5468-80.

27. M. Bensch, C.H. Konrad, E. Fleischmann, C. Rae, and U. Glatzel: Mater. Sci. Eng. A, 2013, vol. 577, pp. 179-88.

28. W. Hermann, H.G. Sockel, J. Han, and A. Bertram: in Superalloys 1996: Proceedings of the Eighth International Symposium on Superalloys, R.D. Kissinger, D.J. Deye, D.L. Anton, A.D. Cetel, 
M.V. Nathal, and T.M. Pollock, eds., TMS, Warrendale, 1996, pp. 229-38.

29. M. Fahrmann, W. Hermann, E. Fahrmann, A. Boegli, T.M. Pollock, and H.G. Sockel: Mater. Sci. Eng. A, 1999, vol. 260, pp. $212-21$.

30. R. Morrell, D.A. Ford, and K. Harris: Calculations of Modulus in Different Directions for Single-Crystal Alloys, NPL Report DEPC-MN 004; Technical Report, NPL, 2004.

31. C.K. Bullough, M. Toulios, M. Oehl, and P. Lukáš: in Materials for Advanced Power Engineering 1998: Proceedings of the 6th Liége Conference/Jacqueline Lecomte-Beckers, F. Schubert and P.J. Ennis, J. Lecomte-Beckers, F. Schubert, and P.J. Ennis, eds., Schriften des Forschungszentrums Julich. Reihe Energietechnik/ Energy technology, 1433-5522, Vol. 5, 2; Forschungszentrum Julich: Julich, Germany, 1998, pp. 861-78.

32. D.M. Shah and D.N. Duhl: in Superalloys 1984: Proceedings of the Fifth International Symposium on Superalloys, M. Gell, C.S. Kortovich, R.H. Bricknell, eds., TMS, Warrendale, 1984, pp. $105-14$.

33. R.V. Miner, T.P. Gabb, J. Gayda, and K.J. Hemker: Metall. Trans. A, 1986, vol. 17, pp. 507-12.

34. R.V. Miner, R.C. Voigt, J. Gayda, and T.P. Gabb: Metall. Trans. A, 1986, vol. 17, pp. 491-96.

35. C.D. Allan: PhD Thesis, Massachusetts Institute of Technology, 1995.

36. G.R. Leverant and D.N. Duhl: Metall. Trans., 1971, vol. 2, pp. $907-08$.

37. B.H. Kear and J.M. Le Oblak: J. Phys. Colloq., 1974, vol. 35, pp. $35-45$.

38. L12 Ordered Alloys: Nabarro, F.R.N., Duesbery, M.S., Eds., Dislocations in Solids, Vol. 10; Elsevier, Amsterdam, 1996.

39. A. Nitz, U. Lagerpusch, and E. Nembach: Acta Mater., 1998, vol. 46, pp. 4769-79.

40. R.C. Reed and C.M.F. Rae: in Physical Metallurgy, D.E. Laughlin and K. Hono, eds., Elsevier, Amsterdam, 2014, pp. 2215-90.

41. T.M. Smith, Y. Rao, Y. Wang, M. Ghazisaeidi, and M.J. Mills: Acta Mater., 2017, vol. 141, pp. 261-72.

42. D. Barba, T.M. Smith, J. Miao, M.J. Mills, and R.C. Reed: Metall. Mater. Trans. A, 2018, https://doi.org/10.1007/s11661-018-4567-6.

43. D.J. Crudden, A. Mottura, N. Warnken, B. Raeisinia, and R.C. Reed: Acta Mater., 2014, vol. 75, pp. 356-70.

44. C. Carry and J. Strudel: Acta Metall., 1977, vol. 25, pp. 767-77.

45. C. Carry and J. Strudel: Acta Metall., 1978, vol. 26, pp. 859-70.

46. J.A. Carey, P.M. Sargent, and D.R.H. Jones: J. Mater. Sci. Lett., 1990, vol. 9, pp. 572-75.

47. S.A. Sajjadi and S. Nategh: Mater. Sci. Eng., 2001, vol. 307, pp. $158-64$.

48. D.A. Woodford, D.R. van Steele, K. Amberge, and D. Stiles, in Superalloys 1992: Proceedings of the Seventh International Symposium on Superalloys, R.A. MacKay, S.D. Antolovich, R.W. Stusrud, D.L. Anton, T. Khan, R.D. Kissinger, and D.L. Klarstrom, eds., TMS, Warrendale, 1992, pp. 657-64.

49. D.A. Woodford: Mater. Des., 1993, vol. 14, pp. 231-42.

50. Woodford, D.A.: in Superalloys 1996: Proceedings of the Eighth International Symposium on Superalloys, R.D. Kissinger, D.J. Deye, D.L. Anton, A.D. Cetel, M.V. Nathal, and T.M. Pollock, eds., TMS, Warrendale, 1996, pp. 353-57.

51. J.A. Daleo, K.A. Ellison, and D.A. Woodford: J. Eng. Gas Turbines Power, 1999, vol. 121, p. 129.

52. J. Beddoes and T. Mohammadi: J. Strain Anal. Eng. Des., 2010, vol. 45 , pp. $587-92$.
53. M.V. Nathal, J. Bierer, L. Evans, E.A. Pogue, F. Ritzert, and T.P. Gabb: Mater. Sci. Eng. A, 2015, vol. 640, pp. 295-304.

54. S.L. Semiatin, P.N. Fagin, R.L. Goetz, D.U. Furrer, and R.E. Dutton: Metall. Mater. Trans. A, 2015, vol. 46A, pp. 3943-59.

55. M. Dupeux, J. Henriet, and M. Ignat: Acta Metall., 1987, vol. 35, pp. 2203-12.

56. T.M. Smith, R.R. Unocic, H. Deutchman, and M.J. Mills: Mater. High Temp., 2016, vol. 33, pp. 372-83.

57. H. Rouault-Rogez, M. Dupeux, and M. Ignat: Acta Metall. Mater., 1994, vol. 42, pp. 3137-48.

58. H.J. Frost and M.F. Ashby: Deformation-mechanism maps, 1st ed., Pergamon Press, Oxford Oxfordshire and New York, 1982.

59. R.N. Ghosh, R.V. Curtis, and M. McLean: Acta Metall. Mater., 1990, vol. 38, pp. 1977-92.

60. K.C. Mills: Recommended values of thermophysical properties for selected commercial alloys, Woodhead, Cambridge, 2002.

61. K.C. Mills, Y.M. Youssef, Z. Li, and Y. Su: ISIJ Int., 2006, vol. 46, pp. 623-32.

62. P.N. Quested, R.F. Brooks, L. Chapman, R. Morrell, Y. Youssef, and K.C. Mills: Mater. Sci. Technol., 2009, vol. 25, pp. 154-62.

63. G.B. Olson and C.J. Kuehmann: Scr. Mater., 2014, vol. 70 (25), p. 30.

64. R.C. Reed, T. Tao, and N. Warnken: Acta Mater., 2009, vol. 57 (5898), p. 5913.

65. R. Rettig, N.C. Ritter, H.E. Helmer, S. Neumeier, and R.F. Singer: Modell. Simul. Mater. Sci. Eng., 2015, vol. 23, p. 35004.

66. R. Rettig, K. Matuszewski, A. Muller, H.E. Helmer, N.C. Ritter, and R.F. Singer: in Superalloys 2016: Proceedings of the 13th International Symposium on Superalloys, M.C. Hardy, E.S. Huron, U. Glatzel, B. Griffin, B. Lewis, C. Rae, V. Seetharaman, S. Tin, eds., Wiley, Hoboken, 2016, pp. 35-44.

67. R.C. Reed, Z. Zhu, A. Sato, and D.J. Crudden: Mater. Sci. Eng. A, 2016, vol. 729 (667), pp. 261-78.

68. R.C. Reed, A. Mottura, and D.J. Crudden: in Superalloys 2016: Proceedings of the 13th International Symposium on Superalloys, M.C. Hardy, E.S. Huron, U. Glatzel, B. Griffin, B. Lewis, C. Rae, V. Seetharaman, and S. Tin, eds., Wiley, Hoboken, 2016, pp. 13-23.

69. R. Völkl, E. Fleischmann, R. Rettig, E. Affeldt, and U. Glatzel: in Superalloys 2016: Proceedings of the 13th International Symposium on Superalloys, M.C. Hardy, E.S. Huron, U. Glatzel, B. Griffin, B. Lewis, C. Rae, V. Seetharaman, and S. Tin, eds., Wiley, Hoboken, 2016, pp. 75-81.

70. M. Pröbstle, S. Neumeier, P. Feldner, R. Rettig, H.E. Helmer, R.F. Singer, and M. Goken: Mater. Sci. Eng. A, 2016, vol. 676, pp. 411-20.

71. N.C. Ritter, E. Schesler, A. Muller, R. Rettig, C. Korner, and R.F. Singer: Adv. Eng. Mater., 2017, vol. 19, p. 1700150.

72. M. Segersäll, J. Moverare, K. Simonsson, and S. Johansson: in Superalloys 2012: Proceedings of the Twelfth International Symposium on Superalloys, E.S. Huron, R.C. Reed, M.C. Hardy, M.J. Mills, R.E. Montero, P.D. Portella, and J. Telesman, eds., Wiley, New York, 2012, pp. 215-23.

73. M. Segersäll, D. Leidermark, and J.J. Moverare: Mater. Sci. Eng. A, 2015, vol. 623 , pp. $68-77$.

74. Alabort, E.: PhD thesis, University of Oxford, Oxford, 2015.

75. S. Keshavarz and S. Ghosh: Acta Mater., 2013, vol. 61, pp. 6549-61.

76. Y.S. Choi, M.A. Groeber, P.A. Shade, T.J. Turner, J.C. Schuren, D.M. Dimiduk, M.D. Uchic, and A.D. Rollett: Metall. Mater. Trans. A, 2014, vol. 45A, pp. 6352-59.

77. S. Keshavarz, S. Ghosh, A.C. Reid, and S.A. Langer: Acta Mater., 2016, vol. 114, pp. 106-15. 